Dr. Mohammed Sanat Al harbi \& Dr. Nasser Sulaiman Al harbi

Volume (4) No. (1) 2021

مستوى تضمين مهارات القرن الحادي والعشرين في كتاب الرياضيات للصف

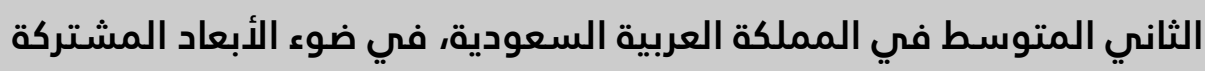
لهيئة تقويم التعليم والتدريب

د. محمد بن صنت بن صالح الحربي \& د. ناصر بن سليليان بن ربيعان الحربي 
مستوى تضمين مهارات القرن الحادي والعشرين في كتاب الرياضيات للصف الثاني المتوسط

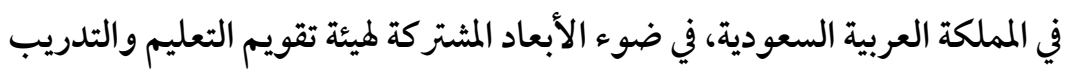

$$
\text { د. محمد بن صنت بن صالح الحربي }
$$

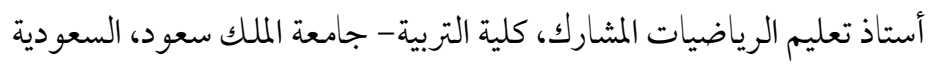

dalhrbi@ksu.edu.sa

د. ناصر بن سليان بن ربيعان الحربي

دكتوراه في مناهج وطرق تدريس الرياضيات، معلم رياضيات بوزارة التعليم، السعودية

n.s.1@ hotmail.com

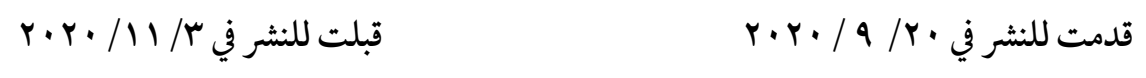

ملخص: هدف البحث إلم التعرف علن مستوئ تضمين مهارات القرن الحادي والعشرين في كتاب

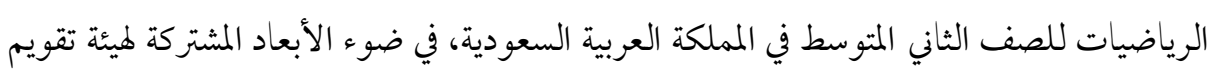

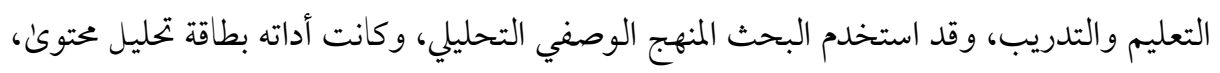

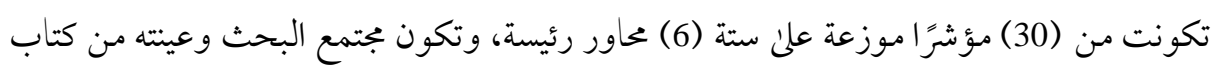

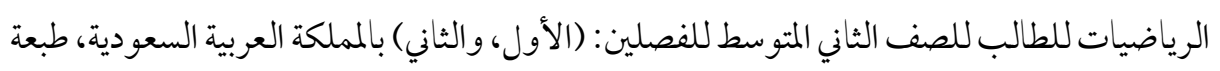

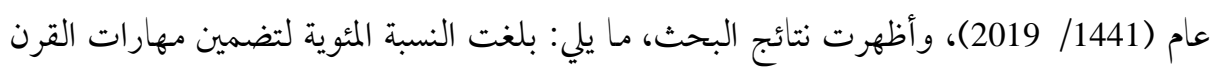

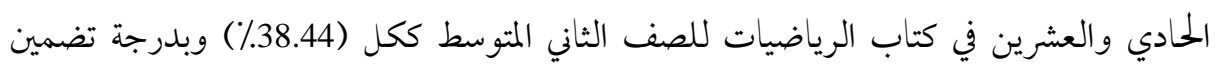

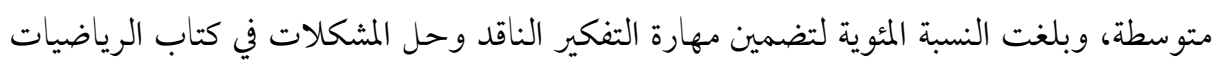
للصف الثاني المتوسط (87.48٪) وبدرجة تضمين عالية؛ حيث توافرت في الفصل الدراسي الأول

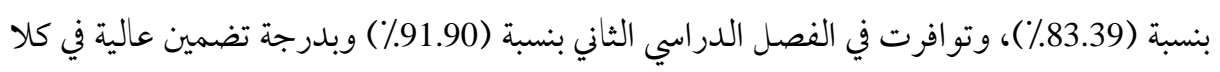

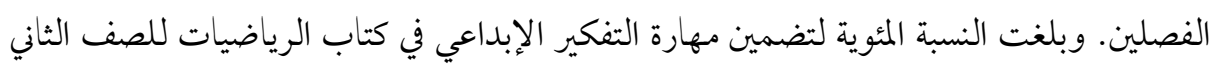

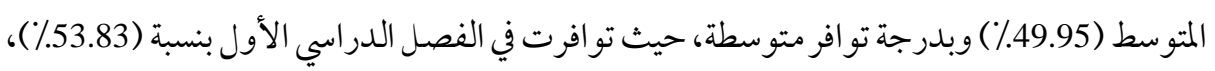

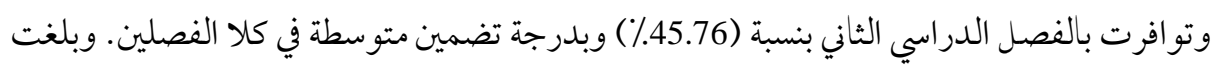

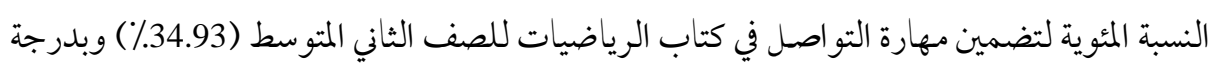


توافر متوسطة، حيث توافرت في الفصل الدراسي الأول بنسبة (39.39٪) وبدرجة تضمين متوسطة،

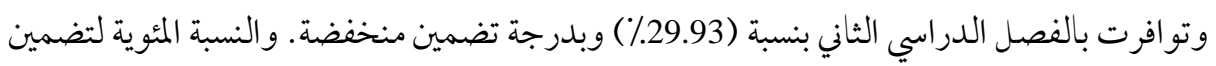

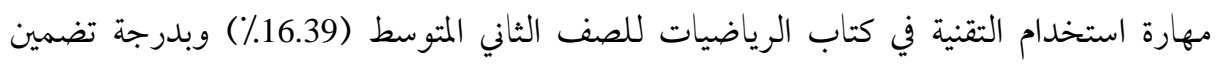

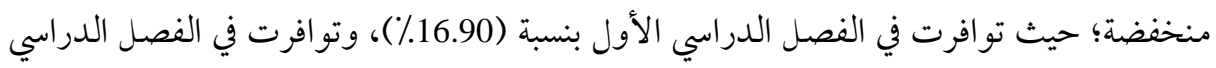
الثاني بنسبة (15.98\%) وبدرجة تضمين منخفضة في كلا الفصلين. وبلغت النسبة المئوية لتضمين مهارة

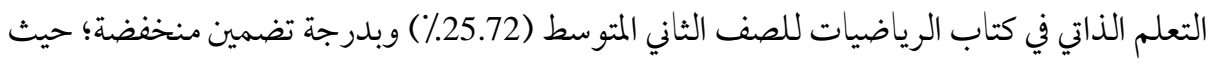
توافرت في الفصل الدراسي الأول بنسبة (23.13٪)، وتوافرت في الفصل الدراسي الثاني بنسبة

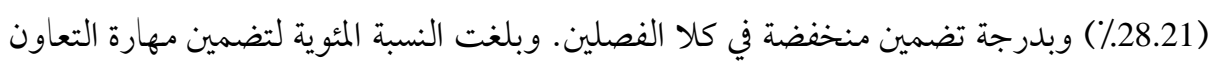

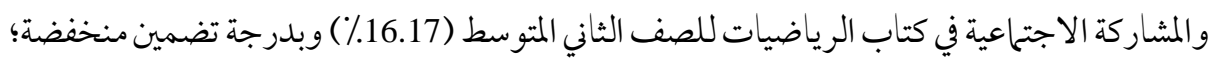
حيث توافرت في الفصل الدراسي الأول بنسبة (13.81/)، وتوافرت باتسبة بالفصل الدراسي الثاني بنسبة (19.23\%) وبدرجة تضمين منخفضة في كلا الفصلين. الكلمات الدلالية: مهارات القرن الحادي والعشرين، كتاب الرياضيات، الصف الثاني المتوسط، الأبعاد

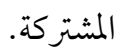


د. محمد بن صنت بن صالح الحربي \& د. ناصر بن سليان بن ربيعان الحربي المجلد (4) العدد (1 ) 2021م

\title{
The level of inclusion of 21st Century Skills in mathematics book for the second intermediate grade in the Kingdom of Saudi Arabia, in light of the mutual dimensions of the Education and Training Evaluation Commission
}

\author{
Dr. Mohammed Sanat Al harbi \\ Associate Professor of Math Education, College of Education, King Saud University, \\ Saudi Arabia \\ dalhrbi@ksu.edu.sa \\ Dr. Nasser Sulaiman Al harbi \\ Ph. Math Education, Mathematics Teacher, Ministry of Education, Saudi Arabia \\ n.s.1@hotmail.com
}

Received in 20th September 2020

Accepted in 3rd November 2020

Abstract: The research aims to identify the level of including the twenty-first century skills in mathematics book for the second intermediate grade in the Kingdom of Saudi Arabia, in light of the mutual dimensions of the Education and Training Evaluation Commission. The research used the descriptive and analytical approach, and its tool was a content analysis card consisting of (30) indicators, they are divided into six (6) main axes, and the research community and its sample are from the mathematics book for the second intermediate class for the two semesters: (first and second) in the Kingdom of Saudi Arabia, edition (1441 / 2019), and the results of the research showed the following: -The percentage of inclusion of twenty-first century skills in the mathematics book for the second intermediate grade as a whole is (38.44\%), with an average degree of inclusion. The percentage of including the skill of critical thinking and problem solving in the mathematics book for the second intermediate grade was $(87.48 \%)$ with a high degree of inclusion; It was available in the first semester by $(83.39 \%)$, and in the second semester it was $(91.90 \%)$ with a high degree of inclusion in both semesters. The percentage of inclusion of the creative thinking skill in the mathematics book for the second intermediate grade was $(49.95 \%)$ with a moderate degree of availability, as it was available in the first semester by (53.83\%), and it was 
available in the second semester at a rate of $(45.76 \%)$ with an average degree of inclusion in both semesters. The percentage of inclusion of communication skill in the mathematics book for the second intermediate grade was (34.93\%) with an average degree of availability, as it was available in the first semester at a rate of (39.39\%) with an average degree of inclusion, and it was available in the second semester at a rate of (29.93\%) with a low degree of inclusion. The percentage of including the skill of using technology in the mathematics book for the second intermediate grade was (16.39\%) with a low degree of inclusion; Where it was available in the first semester by (16.90\%), and in the second semester it was (15.98\%) with a low degree of inclusion in both semesters. The percentage of inclusion of the self-learning skill in the mathematics book for the second intermediate grade was $(25.72 \%)$ with a low degree of inclusion; Where it was available in the first semester by $(23.13 \%)$, and it was available in the second semester by $(28.21 \%)$ with a low degree of inclusion in both semesters. The percentage of including the skill of cooperation and social participation in the mathematics book for the second intermediate grade was (16.17\%) with a low degree of inclusion; Where it was available in the first semester by (13.81\%), and it was available in the second semester by $(19.23 \%)$ with a low degree of inclusion in both semesters.

Keywords: 21st Century Skills, Mathematics Book, Second Intermediate Grade Mutual Dimensions 
يتَّسمُ العصر الحلالي بسرعة التحولات في كافة المجالات، مما أدى إلى ظهور تغيرات متلاحقة،

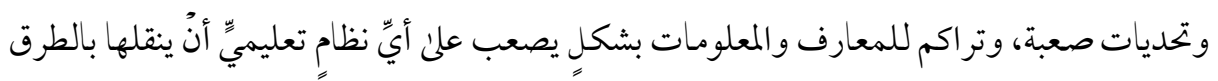

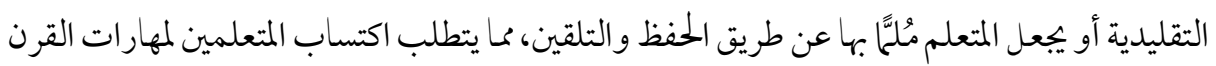
الحادي و العشرين، وذلك لإعداد جيل قادر علن مو اكبة تطورات القرن الحالي ومو اجهة تحدياته.

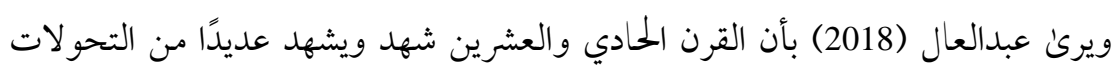
المعرفية والاقتصادية والتكنولوجية، والتي أثرت تأثيرًا بالغًا علن الإنسان من حيث قدراته ومهاراته و كفاياته، حتى أصبح من الملاحظ أن الدول التي تمتلك المقومات المعرفية والاقتصادية والتكنولوجية يمكن أن تحصل على التميز في مجالات الحياة المختلفة، ومن لا يملك هذه المقومات يظل في حاجة لغيره، تابعًا له دائًًا.

لذا شرعت العديد من المؤسسات التربوية في بداية القرن الحادي والعشرين كما يذكر الشهراني وآل محفوظ (2020) إلى إعادة النظر في توجهاتها وخططها لإصلاح النظام التربوي وجميع عناصرهلكي يتو افق مع متغيرات ومتطلبات هذا العصر، وتحقيق تناغمًا إيهابيًا معه من خلال التركيز على المهارات التي ترقئ بالمتعلمين للمشاركة في بناء مجتمع متطور قادر علن مواجهة تحديات هذا العصر المتسارع بالعلم و المعرفة والابتكار.

وقد استجابت رؤية المملكة العربية السعودية 2030 لمتطلبات القرن الحادي والعشرين، حيث اهتمت بتوفير فرص التعليم للجميع في بيئة تعليمية مناسبة في ضوء السياسة التعليمية للمملكة العربية السعودية، ورفع جودة خرجاته، وزيادة فاعلية البحث العلمي، وتشجيع الإبداع والابتكار، وتنمية الشر اكة المجتمعية، والارتقاء بمهارات وقدرات منسوبي التعليم، وذلك من خلال الرفع من مستوىن التعليم تحت شعار "تعليم يُسهم في دفع عجلة الاقتصاد"، وكان من أهم أهدافها ضرورة المواءمة بين خخرجات التعليم، واحتياجات سوق العمل، وتزويد الطلاب بالمعارف، والمهارات اللازمة لوظائف المستقبل، ووضعت قاعدة للتنبؤ بمهارات القرن الحادي والعشرين الواجب إكسابها للجيل القادم 
ليحقق رؤية وأهداف وطنه، وذلك من خلال إدراج تلك المهارات في معايير التعليم، والمناهج الدراسية، وتدريب المعلمين عليها (سلبع، 2018؛ وزارة التعليم، 2019). وعليه فإن استشر اف رؤية مستقبلية وفق رؤية المملكة 2030 لتطوير منظومة التعليم والمناهج، يستدعي سبر أغوار الواقع وتحليله، ومن ثم صياغة الاستراتيجيات والمبادرات والمشاريع المرحلية لتحقيق هذه الرؤية ومتابعة ورصد نجاحها وقياس أثر مخرجاتها ومراجعة آليات جودتها، ومن

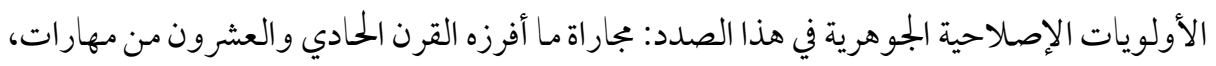
ومتابعة المستجدات العلمية والتقنية والبحثية، وتشجيع الطلاب على مد وتوسيع شبكات تو اصلهم علن المستوى الدولي والعالمي، في ظل اهتمامات مشتركة علن أن يكون أساسها ومنبعها احترام الثقافات والمجتمعات الأخرىن، والتعاون والمشاركة المجتمعية الفاعلة والتقيد بأسس التعامل الأخلاقي في توظيف برامج وتطبيقات التو اصل الاجتماعي لخدمة العلم والثقافة من خلال وضع استراتيجيات

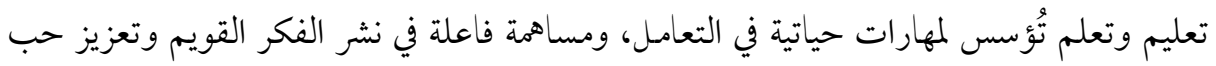
الوطن والفخر به ودحض كل ما من شأنه المساس بهويته وممتلكاته، وإرساء قو اعد صحية لتحقيق السلامة الرقمية من خلال التكامل بين المقررات، وذلك للوقاية من خخاطر الإدمان في استخدام وسائل التو اصل الاجتماعي للحد الذي قد يُؤثر سلبًا علن صحة مستخدميه وأمن فكرهم واستقرار حياتهم (الحصان، 2017)

وحرياً بالقول بأن الثورة المعرفية والتكنولوجية التي يشهدها العصر الحالي ها تأثير مباشر على تعليم وتعلم الرياضيات؛ فلم تعد النظرة نحو الرياضيات علن أنها ذلك العلم المجرد فحسب، أو أنها مادة تعليمية تحتاج إلى قدرات ذات مستويات عالية للتفكي؛ بل أصبح هناك رؤئ استشر افية للأهداف المستقبلية لمناهج الرياضيات بما يو اكب هذا العصر المعلوماتي، وقد أبمعت الدراسات السابقة على أهمية تطوير مناهج الرياضيات بما يتلاءم مع متطلبات القرن الحادي والعشرين تلبية لحاجة العصر الحلالي وتحديات العولمة (محمود، 2015). 
وتعد الرياضيات من أبرز العلوم التي ترتكز عليها تنمية المجتمعات فكريًا وحضاريًا؛ وذلك لأهميتها في تنمية أنواع التفكير عند الطلاب (خليل والنذير، 2019)، كما تعد من العلوم الضرورية للتعامل بين الأفراد في الحياة اليومية؛ فهي تساعدهم علن معرفة مشكلاتهم، ومشكلات بجتمعاتهم، و تسهم في حلها (إبر اهيم، 2002)، كما يؤكد عبيد (2004) على أن الرياضيات هي المحرك الأساسي لما يجري حاليًا من تطورات علمية وتقنية، وما سيحدث مستقبلًا، فأصبح الاهتمام بالرياضيات أحد أهم العوامل لتقدم الدول، فيها أدرك التربويون أهمية دورها في جميع ججالات المعرفة، لذا كان السعي نحو الجودة في تعليم وتعلم الرياضيات هدفًا مهًُا في مختلف الدول من خلال النظريات والمبادرات المتجددة(كساب، 2009) . وقد أجريت العديد من الدراسات البحثية لتطوير المعرفة، وإكساب الطلاب مهارات جديدة وضرورية للعصر الحلالي، وتحديد المهارات المطلوبة للقرن الحادي والعشرين، ومن أهم المؤسسات التي

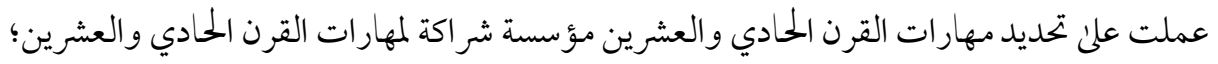
حيث قامت بوضع إطار بالمعايي، والتقويم، والتطوير المهني، فقدمت إطارًا عُرف بإطار التعلم للقرن الحادي و العشرين؛ حيث حددت سبع مهارات للقرن الحادي والعشرين وهي مهارات: التفكير الناقد وحل المشكلة، والابتكار والإبداع، والتعاون و العمل في فريق والقيادة، وفهم الثقافات المتعددة، وثقافة الاتصالات والمعلومات والإعلام، وثقافة الحوسبة وتقنية المعلومات والاتصال، والمهنة والتعلم المعتمد علن الذات(ترلينج وفادل، 2009 / 2013) . وحيث تتجه نُظم التعليم في معظم الدول بشكل عام إلى تحديد عدد من المعارف والمهارات العامة والأساسية لإعداد جيل يلبي طموحاتها، ويحقق رؤاها للنجاح في عصر سريع التغير للتوجه نحو الاقتصاد المبني علن المعرفة والمنافسة فيه، وفي الوقت الذي تشهد فيه المملكة تحولات جذرية في جميع جوانب منظومتها وفي ظل تطلع قيادتها لتحقيق رؤية 2030، والتي أكدت فيها أن المحرك الرئيس لتحقيق الرؤية الكو ادر البشرية. وكون الأبعاد المشتركة لمعايير مناهج التعليم تتضمن: أولويات المنهج، و القيم، والمهارات، لتوفر اتجاهًا تربويًا واضحًا وأساسًا يُستند عليه في تطوير التعلم؛ لبناء قدرات جيل 
المستقبل في المملكة العربية السعودية، الأمر الذي يتطلب العناية بتمكينهم من القيم والمهارات والموضوعات ذات الأولوية؛ لتحقيق طموحاتهم، وطموح بلادهم، قامت هيئة تقويم التعليم و التدريب (2019 أ)، بتحديد أبعادًا عامة مشتركة: (أولويات - قيم - مهارات) ينبغي تمنيتها من خلال

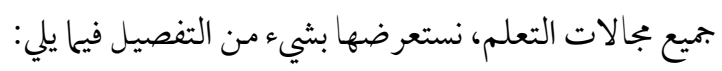

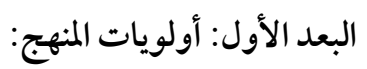
تعبر أولويات المنهج عن التوجهات الوطنية والموضوعات الكبرى ذات الأولوية للمجتمع التي يجب أن تكون حاضرة في مجالات التعلم خلال السنوات القادمة. والأولويات التي يجب أن تستهدفها جميع بجالات التعلم من خلال الجهود الموجهة عبر المستويات والصفوف الدراسية، وتتمثل

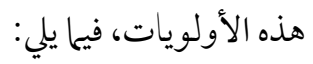
- - مواطنة المسؤولة والتي تعني بأن يكون المتعلم منتميًا لوطنه مو اليًا قيادته، واعيًا بحقوقه وواجباته تجاه أسرته ومجتمعه، وذا فهم عميق لمقومات وطنه ومكتسباته ومدخر اته وتراثه، معتزًا بذلك، ومحافظًا عليه. - - مكانة المملكة ودورها الريادي والتي تعني بأن يكون المتعلم واعيًا بمكانة المملكة العربية السعودية عربيًا وإسلاميًا وعالميًا، ودورها الريادي في كافة المجالات، وبخاصة في تعزيز القيم الإسلامية ذات البعد الحضاري، وخدمة الحرمين الشريفين، مستوعبًا القدرات التنافسية

$$
\text { لو طنه وأثرها في التنمية. }
$$

- - - التنمية المستدامة والتي تعني بأن يكون المتعلم قادرًا على تطوير مواهبه ومهاراته لإنتاج مبادرات ريادية، مدركًا أهمية الإفادة من الكفاءات المختلفة في مسارات التنمية، ساعيًا في العناية بصحته وتطبيق مبادئ الأمن والسلامة، مسهًا في حماية البيئة وتنميتها وحل 


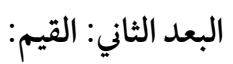

تؤكد معايير مناهج التعليم علن بناء منظومة من القيم لدئ الطالب تمكّنه من تحقيق طموحه بحياة كريمة تحيطها السعادة، ويسودها الاطمئنان والإنتاج. وترتبط هذه القيم بتعزيز انتحاء الطالب لدينه ووطنه وقيادته، وإدراكه للهوية الوطنية، والتزامه العدالة والوسطية واحترام الآخرين، وتتمثل

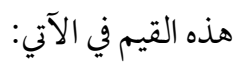

- تقوئ الله والتي تعني بأن يكون المتعلم حريصًا علن تعزيز الوازع الديني لديه، وتزكية نفسه

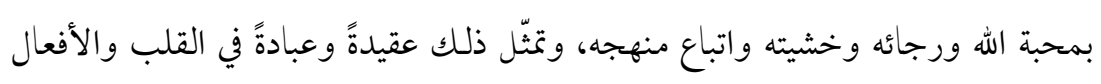

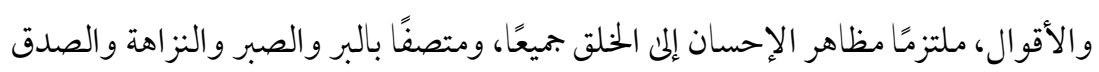

$$
\text { والإخلاص والرحمة والإيثار والتعاون وبذل المعروف. }
$$

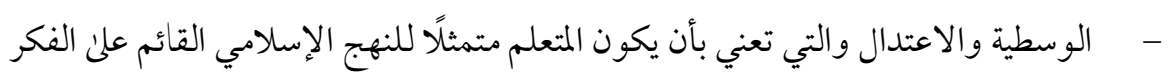
الوسطي المعتدل بها يتضمنه من تسامح ويسر ومرونة ورفع المشقة وعدل ومساواة ورفق،

$$
\text { متقبلًا الآخرين ومستعدًا للتعايش معهم. }
$$

- تقدير الذات والتي تعني بأن يكون المتعلم محترمًا ذاته متقبلًا لها، ومحافظًا عليها، واثقًا بنفسه، وساعيًا للارتقاء بها إلى أقصى إمكاناتها، متصفًا بالر ضا و الطمأنينة والشعور بالنجاح و التميز ئريز

$$
\text { و النظر للحياة والمستقبل بتفاؤل وطموح. }
$$

- - الشغف المعرفي و التي تعني بأن يكون المتعلم مقدرًا للعلم والعلماء في جميع المجالات، ومثابرًا

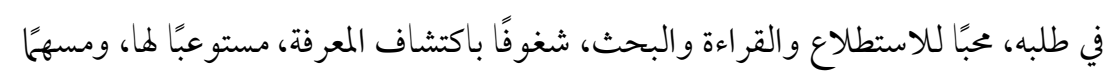

في إنتاجها.

- - تقدير العمل وإتقانه والتي تعني بأن يكون المتعلم مقدّرًا السعي والجد والاجتهادو الانضباط وجودة الممارسة، مُتحليًا بأخلاق المهنة وقيم العمل والنزاهة والصدق والأمانة والابتكار

$$
\text { والتميز. }
$$


- - المسؤولية والتي تعني بأن يكون المتعلم قادرًا علن الوفاء بالالتزامات والواجبات، مدركًا

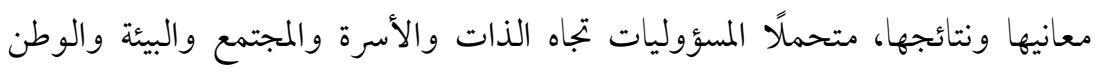

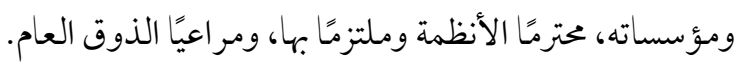

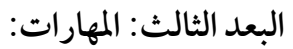

تتشكل المهارات من مجموعة القدرات الذهنية والعاطفية والحركية التي تهيئ الطلاب للحياة

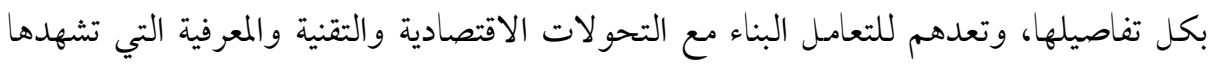

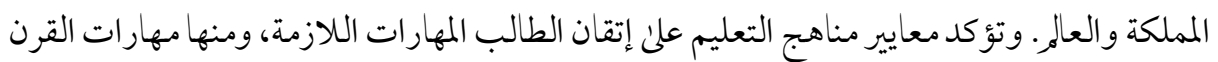

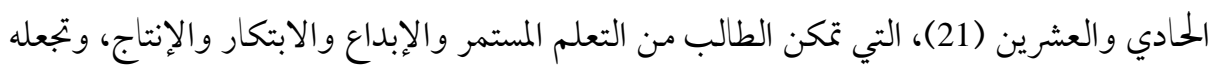
قادرًا علن المشاركة الفاعلة في تحقيق رؤية وطنه والمساهمة في برابجها ومستهدفاتها، وتعده لوظائف المانف

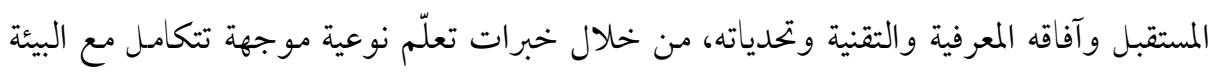
المعرفية لكل مجال تعلم، وتتمثل هذه المهارات في الآتي: - - التفكير الناقدوحل المشكلات: التفكير والتأمل والتقويم باستخدام قو اعد الاستدلال العقلي

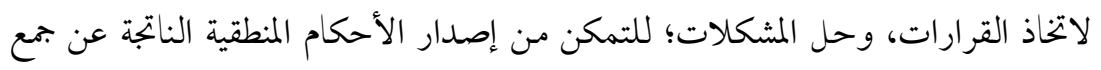

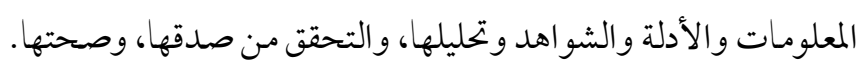
- - التفكير الإبداعي: إنتاج أفكار أصيلة وحلول مبتكرة وبدائل متنوعة ترتبط ارتباطًا وثيقًا

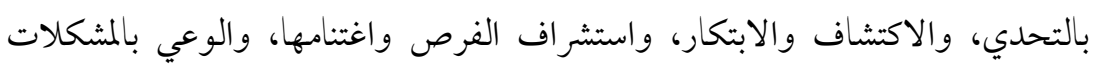

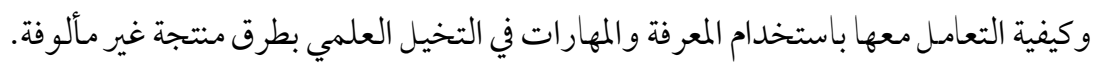

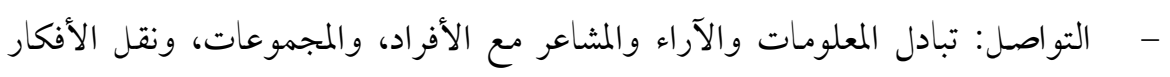
بصورة لفظية وغير لفظية، والتفاعل الإييابي في المواقف التواصلية بكفاءة من خلال

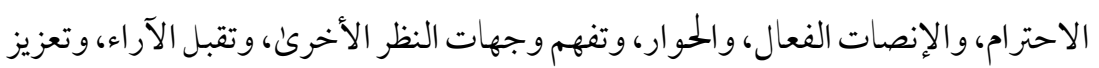
القيم الإنسانية الداعية إلى تنمية الحضارة الإنسانية وإثرائها. 
- استخدام التقنية: استخدام التقنية الرقمية بكل أشكاها ووسائطها وتبادل بياناتها، وإنتاجها في صيغ متعددة، وتحليلها وتقويمها، واستيعاب التحولات المعرفية والتقنية والوسائط

\section{الإعلامية.}

- - التعلم الذاتي: المثابرة في البحث و التقصي بدافع ذاتي وتعلم كيفيات التعلم، من خلال إدراك الأهداف وتحديدها، واختيار طريقة التعلم الملائمة وإيجاد المصادر اللازمة، وتوظيف التقنية وتطبيقاتها للوصول إلى المعارف والمعلومات وتنمية القدرة علن تحليلها واستيعابها وإنتاجها. - - التعاون والمشاركة المجتمعية: العمل بنجاح مع الآخرين، ومساندتهم، والمساهمة في إنجاز المهام ضمن فريق عمل؛ لرفع مستوى جودة الحياة الإنسانية والبيئية والمساهمة بفاعلية في

$$
\text { تحقيق هدف المجموعة، مع الاحترام، والإنتاج. }
$$

وتؤكد البلوي، والبلوي (2019) أهمية مهارات القرن الحلادي والعشرين؛ حيث تذكر أن تعليم مهارات القرن الحادي والعشرين لا يدور حول تعليم استراتيجية أو أداة بعينه، وإنها حول مشاركة

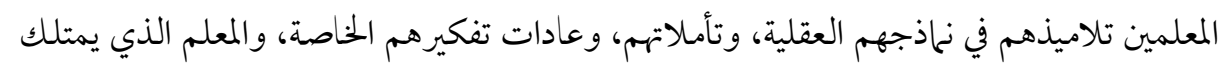
مهارات القرن الحادي والعشرين قادر علن مزج تلك المهارات بالمحتوئ الأكاديمي، وتوفير تطبيقات وعمليات تساعد في إكساب تلاميذهم لمهارات القرن الحادي و العشرين، والتي تمنحهم مفاتيح النجاح في المستقبل. "ومن أجل جعل مهارات القرن الحادي والعشرين ذات جدوئ لطلاب معيّنين، فإن المفتاح

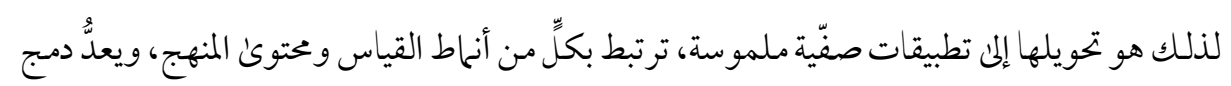
هذه المهارات العميقة في عملية إعداد خريطة المنهاج طريقة طبيعية لضمان تطويرها الحقيقي في غرفة

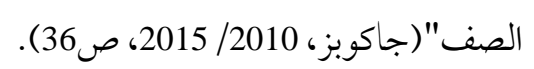

كما يذكر الحريري (2020) إن المشاركة في تنمية التعلم في القرن الحادي و العشرين هيكلة شاملة تهدف إلى دمج هذه المهارات وإدخالها في المنهج؛ لأن منهج القرن الـحادي والعشرين يجب أن يشتمل علن خليط من مهارات المعرفة، والتفكير، والتجديد، والإصلاح، والمعلومات، والاتصال، 
والتكنولوجيا، مع خبرة الحياة في سياق الأكاديمية في الألفية الثالثة مثل: الثفكير الناقد وحل

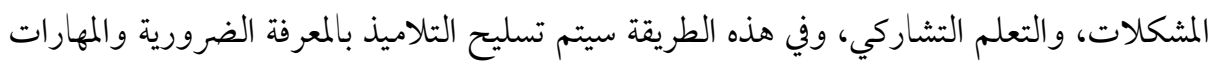
الحياتية التي تساعدهم في النجاح في حياتهم. وقد حظي موضوع مهارات القرن الحادي والعشرين باهتمام الباحثين، حيث تم تناولها بالعديد

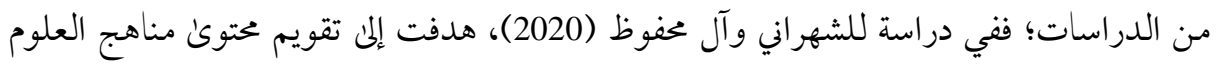
بالمرحلة المتوسطة بالمملكة العربية السعودية، في ضوء مهارات القرن الحادي والعشرين، وأظهرت

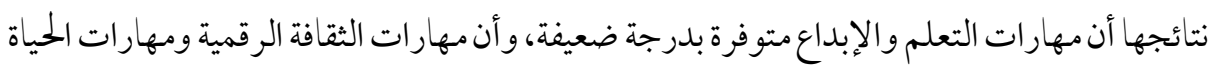

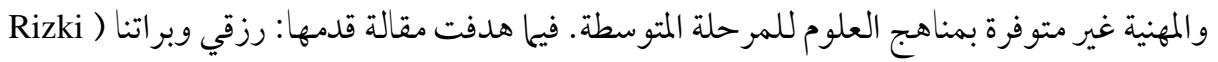

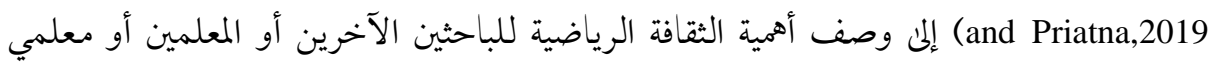

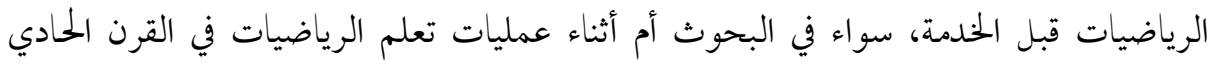

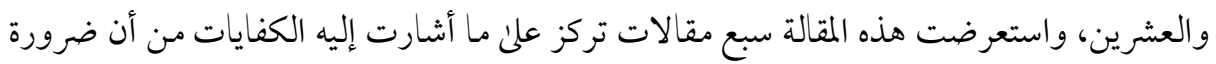

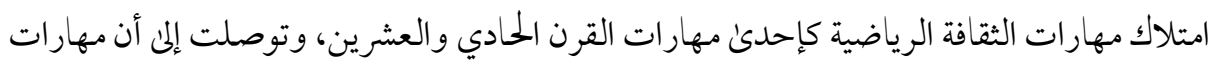

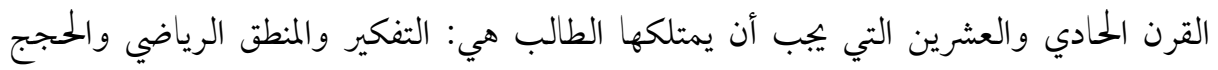

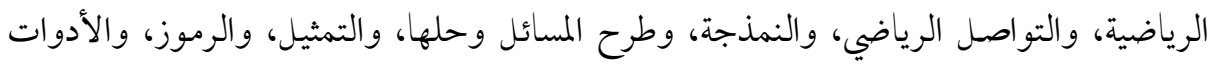

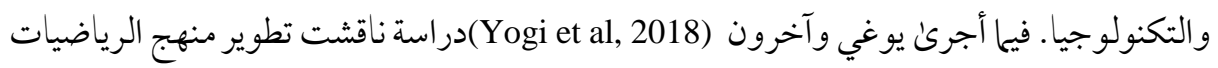

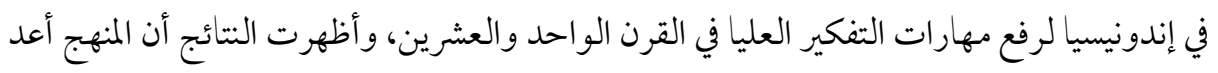

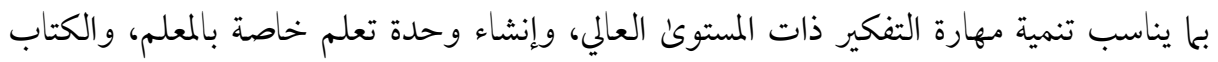

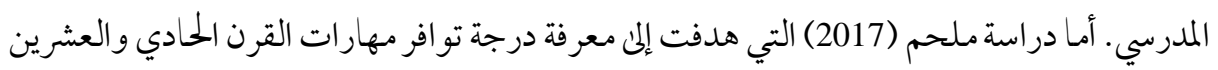

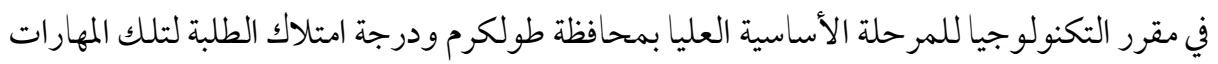
من وجهة نظرهم، أظهرت نتائجها أن مهارات الحياة والعمل قد بلغت 46.4/من النسبة الكلية للمهارات أي أنها أكثر المهارات المتوافرة في مقرر التكنولوجيا، ومهارات التعلم والابتكار جاءت في

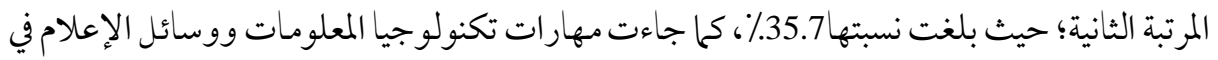


المرتبة الثالثة من حيث توافرها في المقرر وقد بلغت النسبة المئوية لها17.9٪. فيا هدفت دراسة قر افميجير، وآخرين (Gravemeijer et al, 2017) إلى معرفة ما ينبغي أن تكون عليه مناهج الرياضيات لمو اجهة التقدم التقني والعصر الرقمي، واكتساب الطلاب مهارات القرن الحادي والعشرين، وجاءت أهم نتائجها تبني مهارات القرن الحادي والعشرين كأهداف لتعليم الرياضيات للمستقبل، وأن الرياضيات لها قيمة حقيقية واقعية، وأهمية ربط الرياضيات بالعمل و الحياة اليومية، وذلك بالاعتماد علئ مهارات القرن الحادي والعشرين في تعلم الرياضيات، وهدفت دراسة سبحي (2016) إلى التعرف علني مدى تضمين مهارات القرن الحادي والعشرين في مقرر العلوم المطور للصف الأول المتوسط بالمملكة العربية السعودية، وأظهرت نتائجها انخفاض مستوئ تضمين مقررات العلوم المطورة لمهارات القرن الحادي و العشرين بنسبة بلغت86.22\%؛، وقد جاءت مهارات التفكير الناقد وحل المشكلات في المرتبة في المرتبة الأولن بنسبة بلغت72.6\%، وحلت مهارات المهنة والتعلم المعتمد علن الذات في المرتبة الثانية بنسبة بلغت9.28\%؛، وجاءت مهارات ثقافة الاتصالات والمعلومات والإعلام في المرتبة الثالثة بنسبة.18.٪، تلتها مهارات الابتكار والإبداع بنسبة.25.25، وهدفت دراسة الغامدي (2015) إلى التعرف علن درجة توافر مهارات القرن الحلدي والعشرين اللازم تو افرها في محتون كتب الرياضيات للصفوف العليا للمرحلة الابتدائية. وأظهرت نتائجها أن النسبة المئوية لتو افر مهارات القرن الحادي والعشرين بلغت21.2٪ في محتوى كتب الرياضيات للصف الرابع الابتدائي وتوفر بدرجة متوسطة، بينما بلغ2.2\% في محتون كتب الرياضيات للصف الخامس الابتدائي وتوفر بدرجة متوسطة، وبلغ 39.7٪ في محتوئ كتب الرياضيات للصف السادس الابتدائي وتوفر بدرجة منخفضة، حيث بلغ

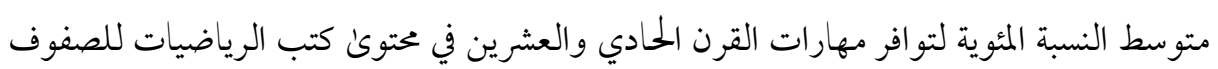
العليا للمرحلة الابتدائية41.0٪ وتوفر بدرجة متوسطة، وتوزع بنسب متفاوتة علن سبعة بجالات رئيسة، جاءت مرتبة تنازليًا وفق نسبة توافرها في محتوئ كتب الرياضيات للصفوف العليا للمرحلة الابتدائية، كما يلي: مهارات التفكير الناقد وحل المشكلات جاءت في المرتبة الأولى بنسبة مئوية بلغت78.3\% وتوفرت بدرجة عالية، مهارات المهنة والتعلم المعتمد جاءت في المرتبة الثانية على الذات 
بنسبة مئوية بلغت 58.6٪ وتوفرت بدرجة متوسطة، مهارات الابتكار والإبداع جاءت في المرتبة الثالثة بنسبة مئوية بلغت8.87٪ وتوفرت بدرجة متوسطة، مهارات ثقافة الاتصالات والمعلومات و الإعلام جاءت في المرتبة الرابعة بنسبة مئوية بلغت36.5٪ وتوفرت بدرجة منخفضة، التعاون والعمل في فريق والقيادة جاءت في المرتبة الخامسة بنسبة مئوية بلغت32.3٪ وتوفرت بدرجة منخفضة، فهم الثقافات المتعددة جاءت في المرتبة السادسة بنسبة مئوية بلغت19.4\% وتوفرت بدرجة منخفضة جدًا، ثقافة الحوسبة وتقنية المعلومات والاتصال جاءت في المرتبة السابعة بنسبة مئوية بلغت3.4٪ وتوفرت بلدرجة منخفضة جدًا. وقام المواس، وآخرون ( El Mawas et al,2012) بورقة بحثية بعنوان " Count With Me!" "قم بالعدمعي!" من خلال تقديم لعبة فيديو تعليمية قائمة علن الكمبيوتر تقوم بتدريس مفاهيم الرياضيات، حيث يتم تقديم استطلاع حول كيفية دعم اللعبة لنطوير مهارات المتعلمين في القرن الحادي والعشرين مثل: حل المسائل والتعلم الموجه ذاتيًا، وبناء المعرفة ومحو الأمية الرقمية، وأظهرت نتائج الدراسة أن الغالبية العظمى من الطلاب الذين شاركوا في دراسة الحالة اكتسبو امهارات القرن

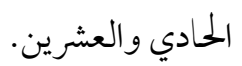

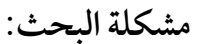

"يعدُّ اتجاه مهارات القرن الحادي والعشرين من الاتجاهات التي بدأت تنال اهتمامًا من التربويين، وذلك بهدف دعم الطلاب في الجامعة والحياة الوظيفية، من حيث إتقان كلاً من : المحتوين،

$$
\text { والمهارات" (الهويش، 2018، ص250). }
$$

"لذلك كان من الضرورة الاهتحام بمهارات القرن الحادي والعشرين، وتضمنينها في المحتوىن" التعليمي؛ للارتقاء بمستوى المتعلمين، لرفع إنتاجيتهم وتوسيع خبراتهم في اكتساب المعارف والمهارات

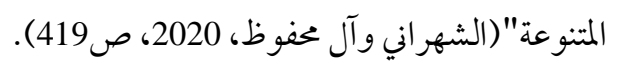

وأيضًا يدعم أهمية هذه الدراسة ما أفرزته جائحة كورونا من تغيير في نمط التعليم وأساليبه

وحاجة المتعلم للاعتماد علئ نفسه، و استخدام التقنية ومهارة التعلم الذاتي ومهارات التفكير، والتو اصل وغيرها من مهار ات القرن الحادي و العشرين. 
ورغم أن الدول العربية ومنها المملكة العربية السعودية، قد حققت قفزات كبيرة في مجال إتاحة

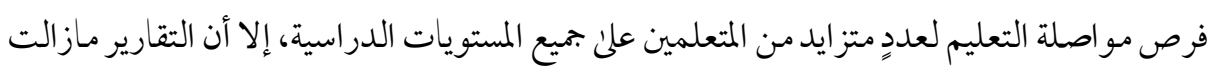

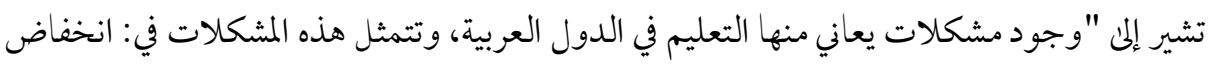

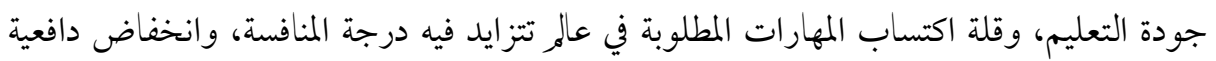

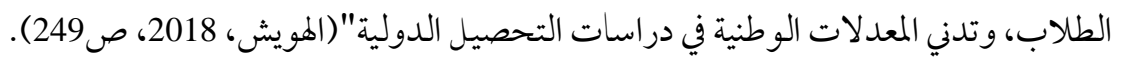

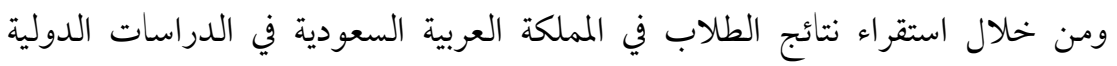

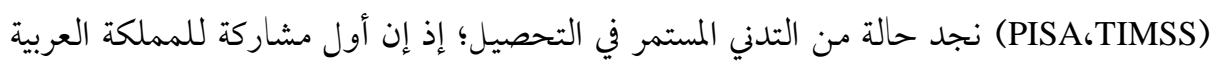

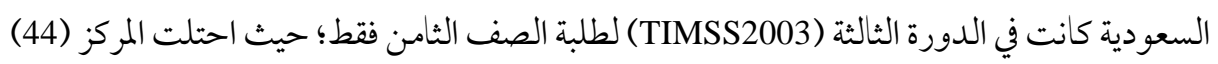
من بين (46) بلدًا مشاركًا بمتوسط (332) نقطةً، وذلك أقل بكثير من المتوسط العالمي (467) نقطةً،

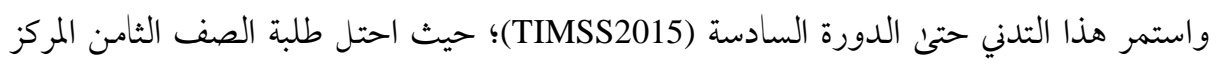

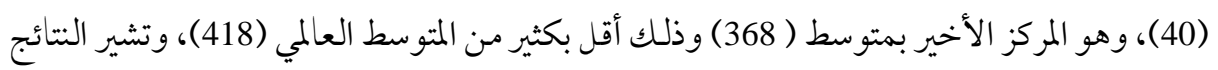

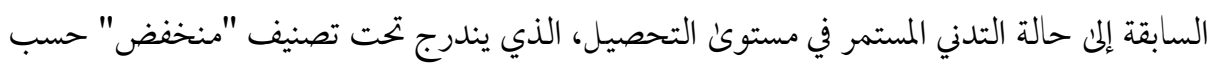

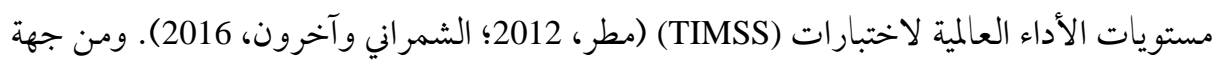

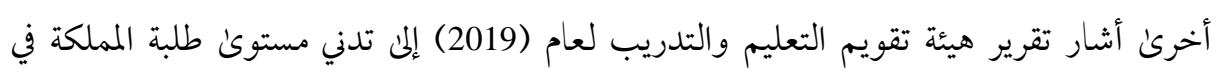

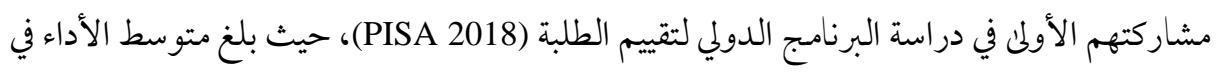

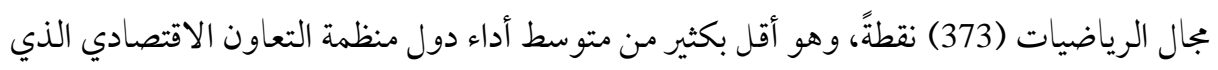

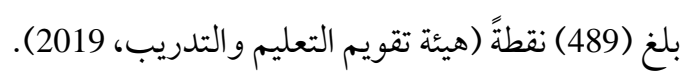

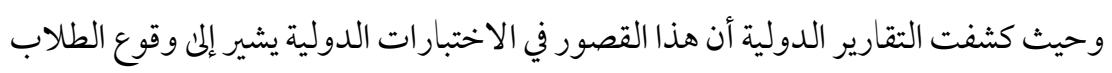

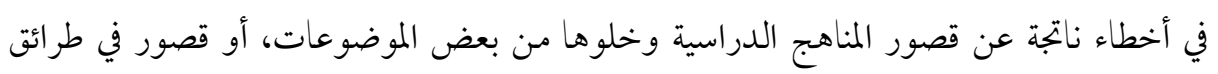

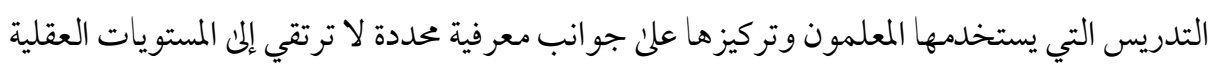
العليا، التي تزخر بها أسئلة الاختبارات الدولية، والتي يشكل مستوئ التطبيق ومستونئ الاستدلال فيها (65 \%) مما يتطلب امتلاك المتعلم لمهارات القرن الحادي والعشرين (العوضي وآخرون، 2011). 
واستجابة لتوصيات المؤتمر العلمي الخامس والدولي الثالث لكلية التربية - جامعة بورسعيد "المدرسة المصرية في القرن الحادي والعشرين، في ضوء الاتجاهات العالمية للتعليم" والمنعقد في الفترة من 16- 17 أبريل 2016، والذي جاء من أهم توصياته: ضرورة اهتمام صناع القرار عند بناء الخطط الدراسية بمهارات القرن الحادي و العشرين، ومحاولة التركيز علن الطرق والوسائل الحاصة بتلبية تلك بك بكريك المهارات عند تصميمهم لاستراتيجيات العمل، وحيث أوصت العديد من الدراسات بضرورة الاهتحام بتضمين مهارات القرن الحادي والعشرين في محتوئ كتب التعليم العام كدراسات (الدوسري، 2017؛ (Gravemeijer et al. ,2017؛ Drake and Reid,2018؛ 2016؛ 2018؛ الغنامدي، وحيث إن الصف الثاني المتوسط (الثامن) هو أحد الصفوف المستهدفة بدراسة الاتجاهات الدولية في الرياضيات والعلوم Trends in International Mathematics and Science Study (TIMSS)؛ ولأهمية المرحلة المتوسطة باعتبارها مر حلة انتقالية في حياة الطالب تسعى لتثبيت وتوسيع المهارات، والمعارف الأساسية التي اكتسبها الطالب في المرحلة الابتدائية، كما أنها أساس تبنى عليه مر احل التعليم اللاحقة، وتنمو في هذه المرحلة قدرة الطلاب علن استيعاب المفاهيم المجردة، مما يساعد على إكسابهم المهارات المختلفة التي تساعدهم على التكيف مع مجتمعهم (الغامدي وعبدالجواد،

وفي ضوء ما سبق تتحدد مشكلة البحث في الكشف عن مستوى تضمين مهار ات القرن الحلدي و العشرين في كتاب الرياضيات للصف الثاني المتوسط في المملكة العربية السعودية، في ضوء الأبعاد المشتركة لهيئة تقويم التعليم والتدريب.

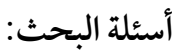

سعى البحث إلى الإجابة على الأسئلة التالية: ا - ما مهارات القرن الحادي و العشرين اللازم تو افرها في محتوى كتاب الرياضيات للصف الثاني المتوسط، في ضوء الأبعاد المشتر كة لهيئة تقويم التعليم والتدريب؟ 
ץ- ما مستوئ تضمين مهارات القرن الحادي والعشرين في محتوى كتاب الرياضيات للصف

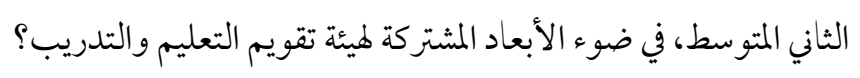

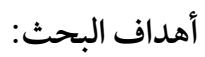

- بناء قائمة بمهارات القرن الحادي والعشرين ومؤشرات تحقق كل مهارة، في ضوء الأبعاد المشتركة لهيئة تقويم التعليم والتدريب اللازم توفرها في محتوى كتاب الرياضيات للصف بهن الثاني المتوسط بالمملكة العربية السعودية. - الكشف عن مستوى تضمين محتوئ كتاب الرياضيات للصف الثاني المتوسط لمهارات القرن الحادي والعشرين، في ضوء الأبعاد المشتركة لهيئة تقويم التعليم والتدريب.

- - تنطلق من أهمية مهارات القرن الحادي والعشرين، والتي يعد تناولها مطلبًا رئيسًا لمواكبة التوجهات الحديثة التي تنادي بربط خخرجات التعليم بمتطلبات سوق العمل. - يتسق البحث مع توجهات وزارة التعليم في دعم رؤية المملكة العربية السعودية (2030)، التي تؤكد علن أهمية إكساب المتعلم مهارات القرن الحادي والعشرين وإعداد جيل قادر علني مو اكبة تطور اته ومواجهة تحدياته. - - قد يزود البحث القائمين علن مراكز التطوير المهني للمعلمين والمعلمات في جوانب القصور

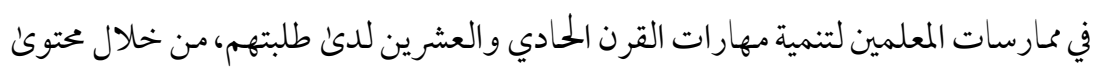
مادة الرياضيات، والعمل على معالجتها وتطويرها، من خلال تقديم بر امج تدريبية وورش عمل مناسبة. 


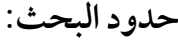

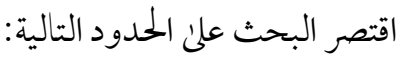

$$
\text { الحدود الموضوعية: }
$$

- تحليل محتوئ كتاب الرياضيات للطالب للصف الثاني المتوسط بالمملكة العربية السعودية (الفصلين: الأول، و الثاني) للعام الدراسي 1441/ 2019، للوصول لمهارات القرن الحادي و العشرين التي يتضمنها الكتاب، في ضوء الأبعاد المشتر كة لهيئة تقويم التعليم والتدريب. مهارات القرن الحادي والعشرين التي حددت في وثيقة الابعاد المشتركة الصادرة عن هيئة تقويم التعليم والتدريب (2019)، والتي حددت فيما يلي: التفكير الناقد وحل المشكلات، التفكير الإبداعي، التو اصل، استخدام التقنية، التعلم الذاتي، التعاون والمشاركة المجتمعية.

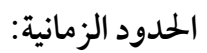
طبق البحث في الفصل الدراسي الأول للعام الدراسي 1441/ 1442علن كتاب الرياضيات للصف الثاني المتوسط بالمملكة العربية السعودية، طبعة عام $1441 / 2019$. مصطلحات البحث:

مهارات القرن الحادي والعشرين (21 Century Skills): عرّفها وارنرو وكور Warner) بأنها: بجموعة المهارات التي يحتاجها الطلاب للنجاح في حياتهم خلال عصر and Kaur, 2017) المعلومات، وتشمل، التفكير الناقد، وحل المشكلات، والتفكير الإبداعي، والتواصل، والتعاون، والإلمام بالتقنية. وتُعرِف بأنها: "مجموعة من مهارات التعلم في القرن الحادي والعشرين وهي: التفكير إلى الناقد وحل المشكلات، والابتكار والإبداع، والتعاون والعمل في فريق والقيادة، وثقافة الاتصالات و المعلومات و الإعلام، وثقافة الحوسبة وتقنية المعلومات و الاتصال، والمهنة والتعلم المعتمد علن الذات،

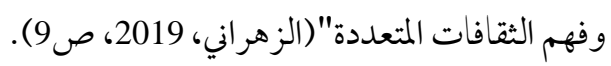

ويُعرِّف الباحثان مهارات القرن الحادي والعشرين إجر ائيًا بأنها: بجموعة المهارات المحددة من قبل هيئة تقويم التعليم والتدريب، ضمن وثيقة الأبعاد المشتركة ضمن المعايير الوطنية لمناهج التعليم 
العام، وهي: التفكير الناقد وحل المشكلات، التفكير الإبداعي، التواصل، استخدام التقنية، التعلم الذاتي، والتعاون والمشاركة المجتمعية. الأبعاد المشتر كة لميئة تقويم التعليم والتدريب: تعرف الأبعاد المشتركة لمعايير ججالات التعلم بأنها: أولويات المنهج، والقيم، والمهارات، التي توفر اتجاهًا تربويًا واضحًا وأساسًا يُستند عليه في تطوير التعلم؛ لبناء قدرات جيل المستقبل في المملكة العربية السعودية، الأمر الذي يتطلب العناية بتمكينهم من القيم والمهارات والموضوعات ذات الأولوية؛ لتحقيق طموحاتهم، وطموح بلادهم (هيئة تقويم التعليم والتدريب، 2018).

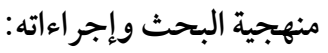

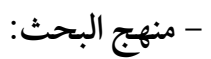
استخدم البحث المنهج الوصفي التحليلي، من خلال تحليل المحتون والذي عرفه بيرلسون: "عبارة عن طريقة بحث يتم تطبيقها من أجل الوصول إلى وصف كمي هادف ومنظم لمحتوئ أسلوب

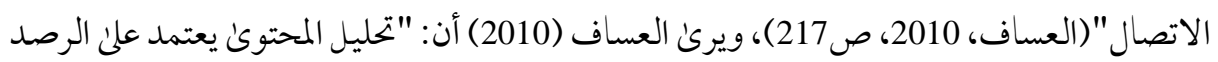

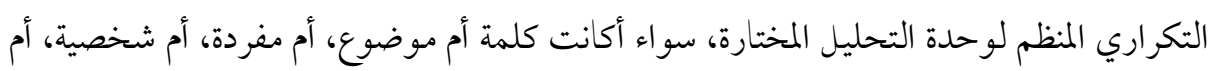

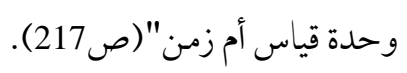
مجتمع وعينة البحث: تكون بجتمع البحث وعينته من كتاب الرياضيات للطالب للصف الثاني المتوسط للفصلين: (الأول، و الثاني) بالمملكة العربية السعودية، طبعة عام (1441/ 2019). أداة البحث:

لتحقيق أهداف البحث، والإجابة علن أسئلته، قام الباحثان ببناء بطاقة تحليل محتوىن، في ضوء مهارات القرن الحادي والعشرين الواردة في وثيقة الأبعاد المشتركة ضمن معايير مناهج التعليم العام و المعدة من قبل هيئة التقويم والتدريب (2019)، وقد تبنى الباحثان المهارات التي حددتها هيئة تقويم التعليم، لكونها انطلقت من رؤية المملكة (2030) واستفادت من الأدب التربوي، والدراسات 
Dr. Mohammed Sanat Al harbi \& Dr. Nasser Sulaiman Al harbi

Volume (4) No. (1) 2021

و البحوث السابقة، والندوات والمؤتمرات العلمية، ومؤسسة شر اكة لمهارات القرن الحادي والعشرين، بتحديدها للمهارات ضمن الأبعاد المشتركة، ولكون هذه الأبعاد خاصة بالمناهج السعودية، وقد اشتملت بطاقة تحليل المحتوىن علن (35) مؤشرًا موزعة علن (6) محاور رئيسة، واستخدمت مقياس (متحقق، غير متحقق) للحكىم على مؤشراتها. صدق أداة البحث: تم عرض بطاقة تحليل المحتوىن علن عدد من المحكِّمين المتخصصين في المناهج وطرق التدريس العامة، وطرق تدريس الرياضيات، وعلم النفس من أعضاء هيئة التدريس في بعض الجامعات السعودية والعربية، وعلن عدد من مشرفي ومشرفات، ومعلمي ومعلمات الرياضيات، وقد بلغ عددهم (15 محكمًا)، وقد تم إجراء بعض التعديلات، وأصبحت الأداة في صورتها النهائية تضم (30) مؤشرًا موزعة علن (6) محاور رئيسة. ثبات أداة البحث: تم التحقق من ثبات بطاقة التحليل من خلال قيام أحد الباحثين بإعادة التحليل لوحدة (المساحة والحجم) من كتاب الرياضيات للطالب للصف الثاني المتوسط الفصل الدراسي الثاني عينة البحث بعد أسبو عين (الثبات عبر الزمن) باستخدام معادلة هولستي. جدول (1) : حساب ثبات تحليل المحتوى بطريقة إعادة التحليل عبر الزمن

\begin{tabular}{|c|c|c|}
\hline معامل الثبات & المحور & p \\
\hline 0.92 & مهارة التفكير الناقد وحل المشكلات & 1 \\
\hline 0.88 & مهارة التفكير الإبداعي & 2 \\
\hline 0.83 & مهارة التواصل & 3 \\
\hline 0.81 & مهارة استخدام التقنية & 4 \\
\hline 0.84 & مهارة التعلم الذاتي & 5 \\
\hline 0.80 & مهارة التعاون و المشاركة المجتمعية & 6 \\
\hline 0.85 & 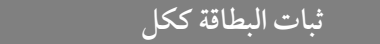 & \\
\hline
\end{tabular}




\section{د. ححمد بن صنت بن صالح الحربي \& د. ناصر بن سليان بن ربيعان الحربي المجلد (4) العدد (1 ) 2021م}

\section{ضوابط التحليل:}

تم التحليل وفقًا لعدد من الضو ابط المحددة، وهي كما يلي:

ا - تم التحليل في إطار المحتوى العلمي لكتاب الطالب، مع استبعاد الغلاف ومقدمة الكتاب

$$
\text { و الفهارس. }
$$

r- وحدة التحليل: تم اختيار الفكرة كوحدة للتحليل؛ لملاءمتها طبيعة البحث.

r- تم تحديد عدد الأفكار التي تظهر فيها كل مهارة، من خلال الاستعانة بوثيقة بجال الرياضيات المعدة من قبل هيئة تقويم التعليم والتدريب ضمن وثيقة معايير بجال تعلم الرياضيات؛ حيث

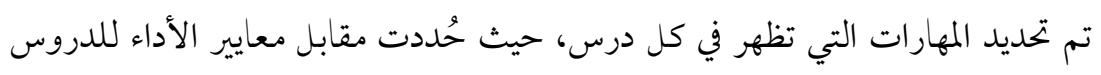
الموجودة في كتاب الطالب وبناء معايير مماثلة للدروس غير الموجودة في وثيقة الهيئة وتحديد المهارات بطريقة مماثلة، ثم تحديد عدد الأفكار في الدروس المقابلة للمعايير؛ ليكون لكل مهارة عدد من الأفكار تبرز فيها هذه المهارة تتضح من الجدول التالي: جدول (2): المهارات وعدد مؤشراتها وعدد الأفكار التي تظهر فيها كل مهارة

\begin{tabular}{|c|c|c|c|c|c|}
\hline \multicolumn{2}{|c|}{} & \\
\hline \\
\hline
\end{tabular}


Dr. Mohammed Sanat Al harbi \& Dr. Nasser Sulaiman Al harbi

Volume (4) No. (1) 2021

\begin{tabular}{|c|c|c|}
\hline \multirow{2}{*}{ مستوى درجة التضمين } & \multicolumn{2}{|c|}{ النسبة المئوية } \\
\hline & إلى & من \\
\hline منخفضة & $\% 33$ & $\%$ \\
\hline متوسطة & $\% 67$ & أكبر من 33٪\% \\
\hline عالية & $\% 100$ & أكبر من 67٪ \\
\hline
\end{tabular}

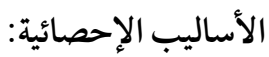

استخدم البحث عددًا من الأساليب الإحصائية المناسبة لبيانات البحث، وهي: التكرارات، و النسب المئوية، والمتوسطات الحسابية؛ لتحديد مستوى تضمين محتوئ كتاب الرياضيات للصف الثاني المتوسط لمهارات القرن الحادي و العشرين وبالتالي الإجابة علن السؤال الثاني، ومعادلة هولتسي؛ للتحقق من ثبات بطاقة الملاحظة من خلال حساب نسبة اتفاق الملاحظين. تحليل نتائج البحث ومناقشتها الإجابة على السؤال الأول: وينص على: ما مهارات القرن الحادي و العشرين اللازم توفرها في محتوى كتاب الرياضيات للصف الثاني المتوسط في المملكة العربية السعودية، في ضوء الأبعاد المشتركة هيئة تقويم التعليم والتدريب؟ تم إعداد قائمة بمهارات القرن الحادي والعشرين اللازم توافرها في محتوكن كتاب الرياضيات للصف الثاني المتوسط بالمملكة العربية السعودية و، وذلك بالاستفادة من كلّ من: وثيقة هيئة تقويم التعليم والتدريب ضمن الأبعاد المشتركة، والأدب التربوي، والدراسات السابقة، كما تم تحديد مؤشرات لكل مهارة من مهارات القرن الحادي والعشرين، ومن ثم تمَّ تحويل القائمة إلى بطاقة تحليل محتوكأ مكونة من (30) مؤشرًا موزعة علن (6) محاور رئيسة. 
د. محمد بن صنت بن صالح الحربي \& د. ناصر بن سليان بن ربيعان الحربي المجلد (4) العدد (1 ) 2021م

جدول (4) قائمة بمهارات القرن الحادي والعشرين اللازم توافرها في كتاب الرياضيات للصف الثاني المتوسط

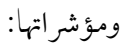

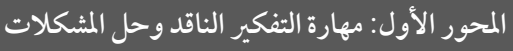

1 2 يدعم المحتوئ التحقق من المعلومات وتقييم دقتها. 3

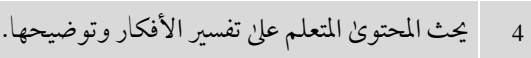
5 يجث المحتوئ المتعلم على تطبيق الحقائق والأدلة والبراهين في مو اقف جديدة. 6 م 6 7 8 يتضمن المحتوئ مواقف لتنمية مهارات اتخاذ القرار. 9 يعزز المحتوئ التأمل لإصدار الأحكام المنطقية.

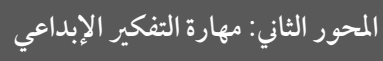

10 يشجع المحتوئ المتعلم علئ توليد البدائل أو الحلول المتنوعة لحل المشكلة الرياضية . 11 يوفر المحتوئ مسائل رياضية مفتوحة وغير روتينية تحل بأكثر من طريقة. 12 يدعم المحتون مرونة التفكير والاستفادة من تنوع المعلومات والأفكار الرياضية المطروحة. 13 يشجع المحتوئ المتعلم علئ اكتشاف النقص وتحديد المشكلة في مسائل الرياضيات والتخطيط لحلها.

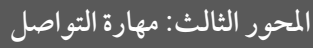

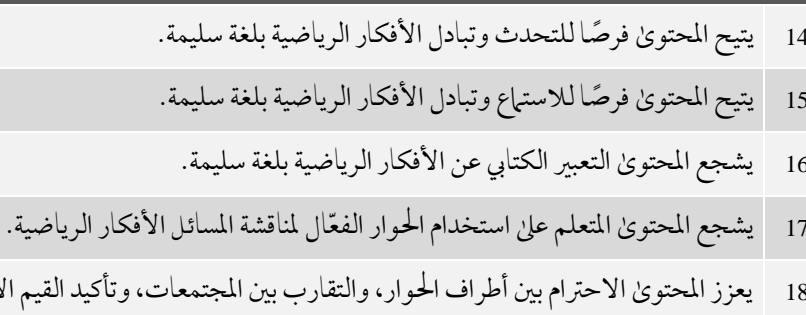

المحور الر ابع: مهارة استخدام التقنية

19 يشجع المحتوكن توظيف التقنية بأشكالها ووسائطها المتعددة بشكل صحيح. 20 يعزز المحتوي المراقبة الذاتية في استخدام التقنية. 21 ينمي المحتوئ الاتجاهات الإيجابية نحو استخدام التقنية. 22 ينبه المحتوى إلمى قو اعد السلوك الأخلاقية عند استخدام التقنية. 


\section{المحور الخامس : مهارة التعلم الذاتي}

\begin{tabular}{|c|}
\hline يشجع المحتوئ المتعلم على تصويب أخطائه ومراقبة تعلمه. \\
\hline يقدم المحتوي أنشطة رياضية تناسب أنهاط التعلم المختلفة. \\
\hline
\end{tabular}

\section{المحور السادس: مهارة التعاون والمشار كة المجتمعية}

$$
26 \text { يقدم المحتوئ أنشطة ومشروعات رياضية تتطلب العمل التعاوني. }
$$$$
27 \text { يشجع المحتوئ العمل في مجموعات مختلفة في القدرات والميول للتعلم والعمل معًا. }
$$

يشجع المحتوئ المتعلم علن المشاركة في وضع استراتيجيات العمل مع الآخرين، والتعلّم منهم و إفادتهم، والحرص علئ

29 يشجع المحتوئ المتعلم علئ المشاركة المجتمعية مع اتباع القواعد و اللو ائح التنظيمية للعمل. 30

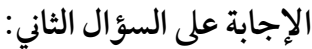

وينص علن: ما مستوى تضمين محتوى كتاب الرياضيات للصف الثاني المتوسط لمهارات القرن الحادي والعشرين في المملكة العربية السعودية، في ضوء وثيقة الأبعاد المشتركة لهيئة تقويم

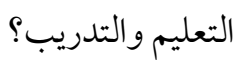

للإجابة علن هذا السؤال تم تحليل محتون كتاب الرياضيات للصف الثاني المتوسط باستخدام بطاقة التحليل المعدة في هذا البحث، وتم حساب التكرارات و النسب المئوية لتحقق مؤشرات كل مهارة والمهارات الكلية: - ماتية 
د. ححمد بن صنت بن صالح الحربي \& د. ناصر بن سليان بن ربيعان الحربي المجلد (4) العدد (1 ) 2021م

\section{أولًا: نتائج التحليل لمجال مهارة التفكير الناقد وحل المشكلات:}

جدول (5) نتائج تحليل محتوئ كتاب الرياضيات للصف الثاني متوسط في ضوء تضمين مهارة التفكير الناقدوحل المشكلات

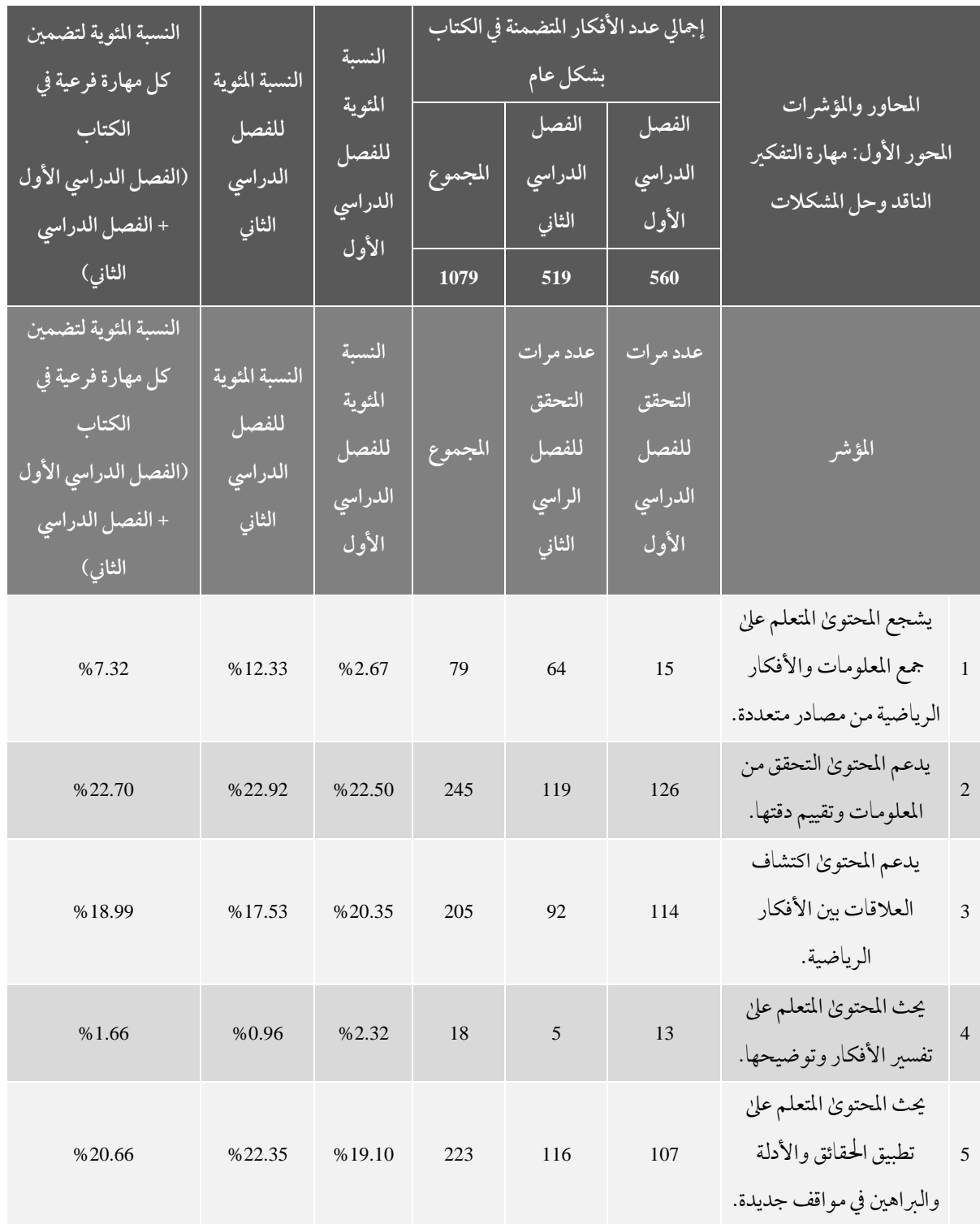


Dr. Mohammed Sanat Al harbi \& Dr. Nasser Sulaiman Al harbi

Volume (4) No. (1) 2021

\begin{tabular}{|c|c|c|c|c|c|c|c|}
\hline كل النسبة المئوية لتضمين & \multirow{3}{*}{ اللفصبة المئوية الدراسي } & \multirow{3}{*}{ اللمألمية اللمصل } & \multicolumn{3}{|c|}{ إجمالي عدد الأفكار المثضمنة في الكتاب } & \multirow{3}{*}{\multicolumn{2}{|c|}{ المحور الأول: مهارة التفكير المؤشرات }} \\
\hline $\begin{array}{c}\text { (الفصل الدراسي الأول } \\
\text { + الفصل الدراسي }\end{array}$ & & & المجموع & الدراسلي الفصلي & الدصل الأول & & \\
\hline الثاني) & & & 1079 & 519 & 560 & & \\
\hline كل مهارة فرعية في المئية لتضمين & اللفبة المئوية الدراسي & 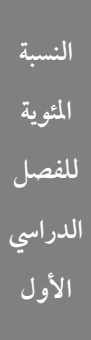 & المجموع & علدد مرات اللحقت & علدم اللحرات & المؤشر & \\
\hline$\% 2.13$ & $\% 1.15$ & $\% 3.03$ & 23 & 6 & 17 & الرياضي المحتوئ الاستدلال & 6 \\
\hline$\% 1.11$ & $\% 1.34$ & $\% 0.89$ & 12 & 7 & 5 & يشجع المحتوئ على تبرير & 7 \\
\hline$\% 1.76$ & $\% 1.54$ & $\% 1.96$ & 19 & 8 & 11 & لتينمية مهارات اتخاذ القرار. & 8 \\
\hline$\% 11.12$ & $\% 11.75$ & $\% 10.53$ & 120 & 61 & 59 & يعزز المحتوى التأمل لإصدار & 9 \\
\hline متضمنة بدرجة عالية & $\% 91.90$ & $\% 83.39$ & 944 & 477 & 467 & المجموع & \\
\hline
\end{tabular}

يتضح من الجمدول (5) بأن النسبة المئوية لتضمين مهارة التفكير الناقد وحل المشكلات في كتاب

الرياضيات للصف الثاني المتوسط بلغت(87.48) وبدرجة تضمين عالية؛ حيث تو افرت في الفصل الدراسي الأول بنسبة(83.39\%) وبدرجة تضمين عالية، وتوافرت بالفصل الدراسي الثاني بنسبة (91.90\%)وبدرجة تضمين عالية؛ حيث نجد أن مؤشر " يدعم المحتوى التحقق من المعلومات وتقييم 
دقتها " جاء بالمرتبة الأولى بنسبة(22.70\%)، فيما جاء مؤشر "يشجع المحتوى علن تبرير النتائج

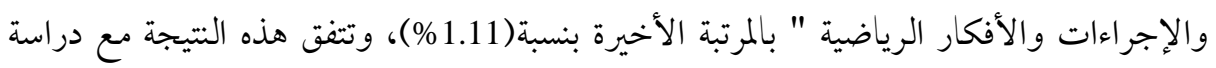

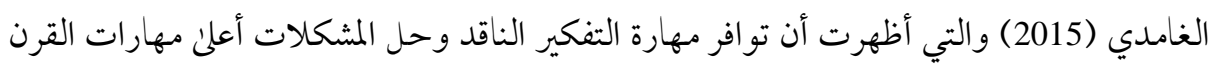

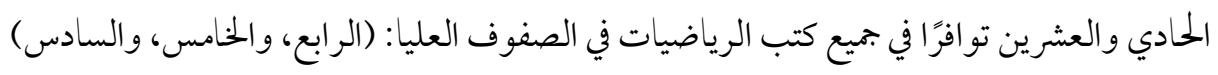

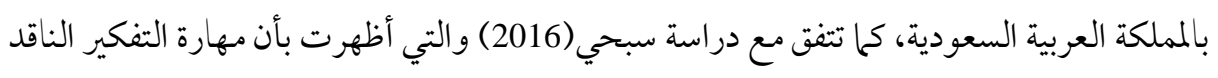

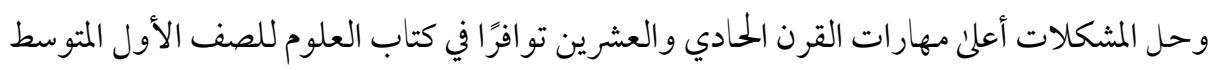

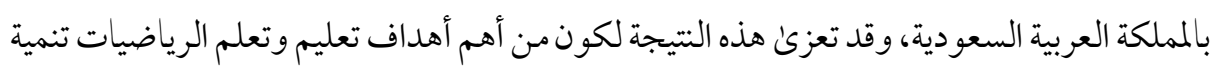

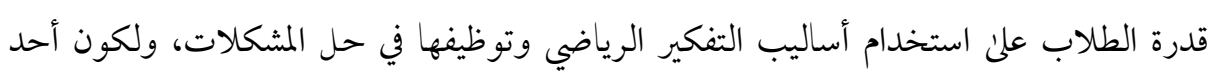

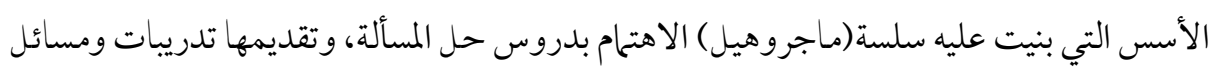

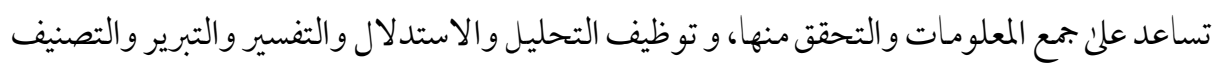

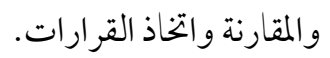


Dr. Mohammed Sanat Al harbi \& Dr. Nasser Sulaiman Al harbi

Volume (4) No. (1) 2021

\section{ثانيًا: نتائج التحليل لمجال مهارة التفكير الإبداعي:}

\begin{tabular}{|c|c|c|c|c|c|c|c|}
\hline \multirow{3}{*}{ 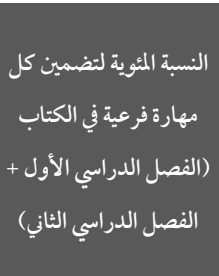 } & \multirow{3}{*}{ اللفية الملئية } & \multirow{3}{*}{$\begin{array}{c}\text { النسبة المئوية } \\
\text { اللفراسي الأول }\end{array}$} & \multicolumn{3}{|c|}{ إجمالي عدد الأفكار المتضمنة في الكتاب بشكل } & \multirow{3}{*}{\multicolumn{2}{|c|}{$\begin{array}{c}\text { المحور الثاني: مهارة الثفكير والمؤشرات } \\
\text { الإبداعي }\end{array}$}} \\
\hline & & & المجموع & الدراسي الثاني & الفصل الدراسي & & \\
\hline & & & 1045 & 497 & 548 & & \\
\hline 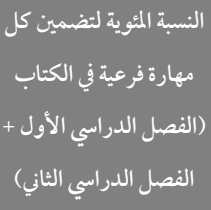 & اللفبة المئوية & $\begin{array}{l}\text { اللنسبة المئوية } \\
\text { الفراسي الأول }\end{array}$ & المجموع & علد التحقر الفصل & للفصل التحقل الدراسي & المؤشر & \\
\hline$\% 20.38$ & $\% 17.90$ & $\% 22.62$ & 213 & 89 & 124 & 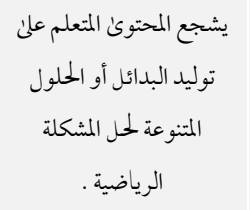 & 10 \\
\hline$\% 3.73$ & $\% 4.22$ & $\% 3.28$ & 39 & 21 & 18 & 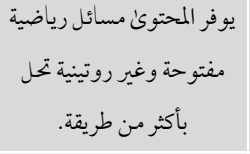 & 11 \\
\hline$\% 1.62$ & $\% 1.81$ & $\% 1.45$ & 17 & 9 & 8 & يدعم المحتوكن مرونة التفكير & 12 \\
\hline$\% 24.21$ & $\% 21.73$ & $\% 26.45$ & 253 & 108 & 145 & 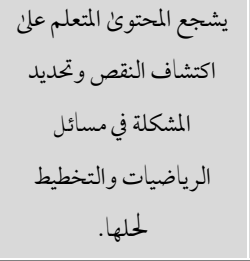 & 13 \\
\hline متضمنة بلدرجة متوسطة & $\% 45.76$ & $\% 53.83$ & 522 & 227 & 295 & المجموع & \\
\hline
\end{tabular}

http://dx.doi.org/10.29009/ijres.4.1.11 
يتضح من الجدول (6) بأن النسبة المئوية لتضمين مهارة التفكير الإبداعي في كتاب الرياضيات للصف الثاني المتوسط بلغت (49.95\%) وبدرجة توافر متوسطة؛ حيث توافرت في الفصل الدراسي

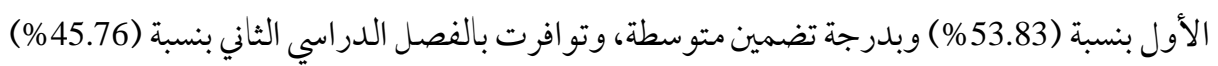

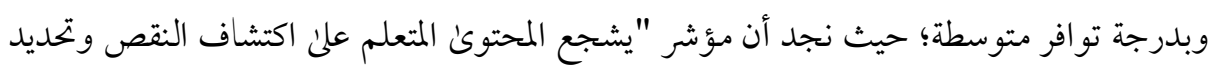

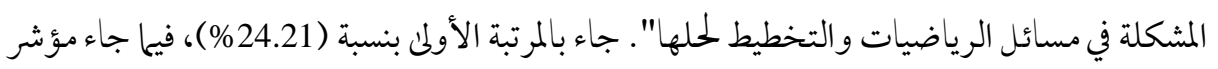

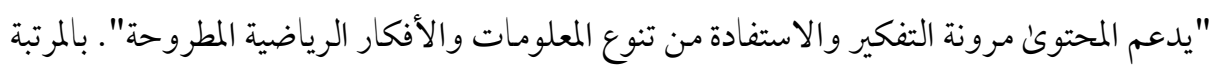

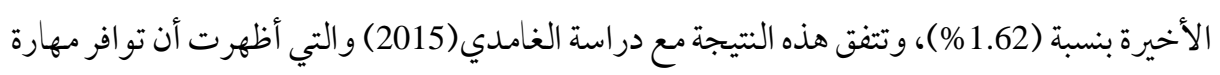

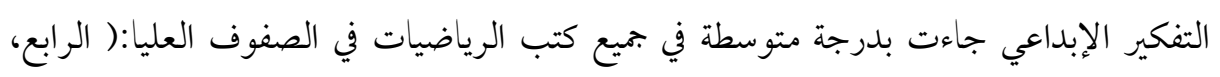

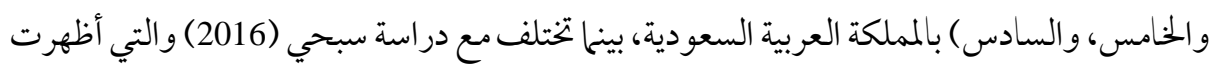

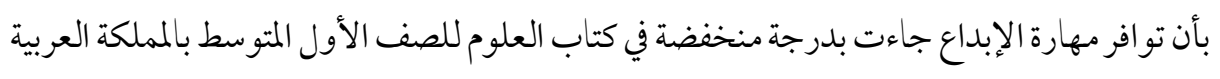
السعودية، وقد تعزى هذه النتيجة لطبيعة مادة الرياضيات وكتبها بالمملكة العربية السعودية والتي تعني

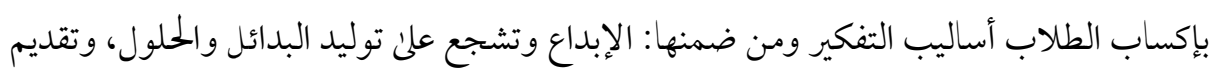
مسائل رياضية مفتوحة تتيح للطالب الإبداع. 
Dr. Mohammed Sanat Al harbi \& Dr. Nasser Sulaiman Al harbi

Volume (4) No. (1) 2021

\section{ثالثًا: نتائج التحليل لمجال مهارة التواصل: - م}

جدول (7) نتائج تحليل محتوى كتاب الرياضيات للصف الثاني المتوسط في ضوء تضمين مهارة التو اصل

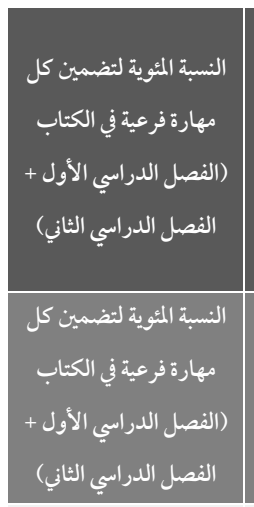

$\% 1.20$

$\% 1.48$

$\% 0.94$

12

7

5

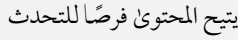
14

$$
\text { سليمة. }
$$

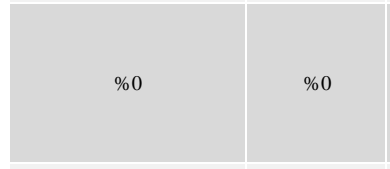

$\% 32.83$

$\% 27.17$

$\% 37.87$

328

128

200

0

يتيح المحتوئ فرصًا للاستماع 15 وتبادل الأفكار الرياضية بلغة سليمة.

يشجع المحتوئ التعبير

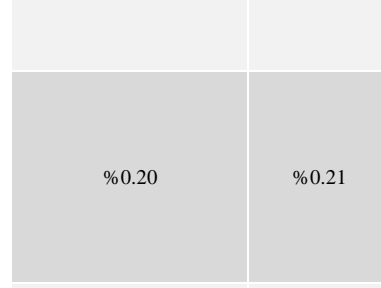

\begin{tabular}{|c|c|c|c|c|c|c|c|}
\hline$\% 0.70$ & $\% 1.06$ & $\% 0.37$ & 7 & 5 & 2 & 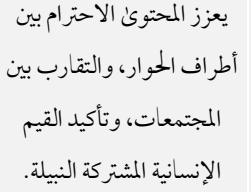 & 18 \\
\hline 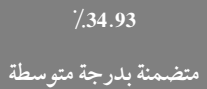 & $\% 29.93$ & $\% 39.39$ & 349 & 141 & 208 & هموع & \\
\hline
\end{tabular}


يتضح من الجدول V) بأن النسبة المئوية لتضمين مهارة التواصل في كتاب الرياضيات للصف الثاني المتوسط بلغت (34.93\%) وبدرجة توافر متوسطة؛ حيث توافرت في الفصل الدراسي الأول بنسبة (39.39\%) وبدرجة تضمين متوسطة، وتوافرت بالفصل الدراسي الثاني بنسبة (29.93\%) وبدرجة تضمين منخفضة؛ حيث نجد أن مؤشر " يشجع المحتوى التعبير الكتابي عن الأفكار الرياضية بلغة سليمة". جاء بالمرتبة الأولى بنسبة (32.83\%)، فيما جاءمؤشر "يتيح المحتوى فرصًا للاستماع وتبادل الأفكار الرياضية بلغة سليمة". بالمرتبة الأخيرة بنسبة (0٪)، وتختلف هذه النتيجة مع دراسة الغامدي (2015) والتي أظهرت أن توافر مهارة التواصل جاءت بدرجة منخفضة في جميع كتب

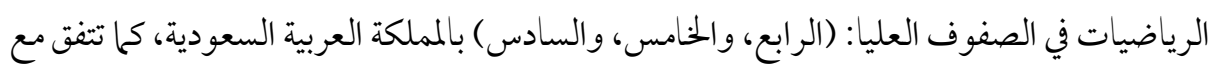
دراسة سبحي (2016) و التي أظهرت بأن مهارة التفكير والاتصال توافرت بدرجة منخفضة في كتاب العلوم للصف الأول المتوسط بالمملكة العربية السعودية، وقد تعزى هذه النتيجة في الفصل الأول؛ لكون التواصل الرياضي أحد معايير المحتون الرياضي، حيث يشير المجلس القومي لمعلمي

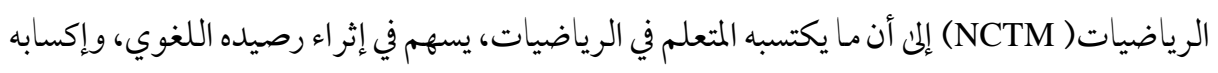

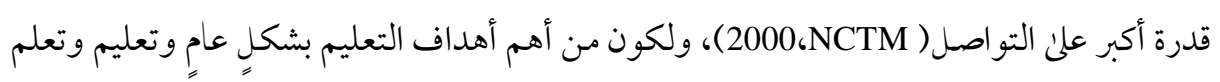
الرياضيات بشكل خاص، فهم المتعلم للمحيط المادي الذي حوله والذي لن يتحقق الاعن طريق

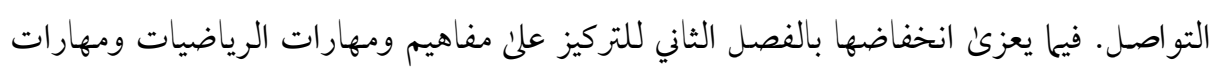
التفكير بشكل أكبر بها يتفق مع طبيعة الرياضيات. 
Dr. Mohammed Sanat Al harbi \& Dr. Nasser Sulaiman Al harbi

Volume (4) No. (1) 2021

\section{رابعًا: نتائج التحليل لمجال مهارة استخدام التقنية:}

جدول (8) نتائج تحليل محتون كتاب الرياضيات للصف الثاني متوسط في ضوء تضمين مهارة استخدام التقنية

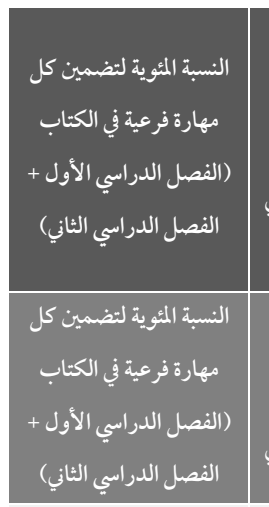

(1)

\begin{tabular}{|c|c|c|c|c|c|c|}
\hline$\% 3.94$ & $\% 2.23$ & $\% 6.10$ & 19 & 6 & 13 & التمنية بأشكالها ووسائطها \\
\hline$\% 3.52$ & $\% 2.69$ & $\% 1.80$ & 17 & 13 & 4 & يعزز المحتوئ المراقبة الذاتية \\
\hline$\% 8.92$ & $\% 8.92$ & $\% 8.92$ & 43 & 24 & 19 & 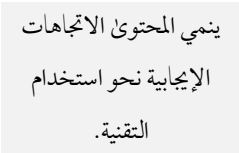 \\
\hline$\% 0$ & $\% 0$ & $\% 0$ & 0 & 0 & 0 & ينبه المحتوكئ إلما قواعد اسلوك الأخلاقية عند \\
\hline متضمنة بدرجة 16.39 & $\% 15.98$ & $\% 16.90$ & 79 & 43 & 36 & المجموع \\
\hline
\end{tabular}

يتضح من الجمدول (8) بأن النسبة المئوية لتضمين مهارة استخدام التقنية في كتاب الرياضيات للصف الثاني المتوسط بلغت (16.39\%) وبدرجة تضمين منخفضة؛ حيث تو افرت في الفصل الدراسي الأول بنسبة (16.90\%) وبدرجة تضمين منخفضة، وتو افرت بالفصل الدراسي الثاني بنسبة(15.98\%) وبدرجة تضمين منخفضة؛ حيث نجد أن مؤشر "ينمي المحتوى الاتجاهات الإيجابية نحو استخدام التقنية" جاء بالمرتبة الأولى بنسبة (8.92\%)، فيما جاء مؤشر "ينبه المحتوى إلى قو اعد السلوك الأخلاقية 
عند استخدام التقنية". بالمرتبة الأخيرة بنسبة (0\%)، وتتفق هذه النتيجة مع دراسة الغامدي (2015) والتي أظهرت أن تو افر مهارات ثقافة الحوسبة وتقنية المعلومات والاتصال جاءت بدرجة منخفضة جدًا في جميع كتب الرياضيات في الصفوف العليا: (الرابع، والخامس، والسادس) بالمملكة العربية السعودية، كما تتفق مع دراسة سبحي (2016) والتي أظهرت بأن مهارات ثقافة الحوسبة وتقنية المعلومات والاتصال توافرت بدرجة منخفضة في كتاب العلوم للصف الأول المتوسط بالمملكة العربية السعودية. وقد تعزىن هذه النتيجة لمراعاة مؤلفي كتب الرياضيات للبيئة التعليمية، وعدم تو افر التقنية بالمدارس والمنازل بالشكل الكافي وعدم امتلاك الطلاب المهارات التقنية الكافية. خامسًا: نتائج التحليل لمجال مهارة التعلم الذاتي: - ل

جدول (9) نتائج تحليل محتون كتاب الرياضيات للصف الثاني المتوسط في ضوء تضمين مهارة التعلم الذاتي

\begin{tabular}{|c|c|c|c|c|c|c|c|}
\hline \multirow{3}{*}{ النهبة المئوية لتضمين كل } & \multirow{3}{*}{ اللفبة المئوية } & \multirow{3}{*}{ النسبة المئوية } & \multicolumn{3}{|c|}{ إجمالي عدد الأفكار المتضمنة في الكتاب بشكل } & \multirow{3}{*}{\multicolumn{2}{|c|}{ 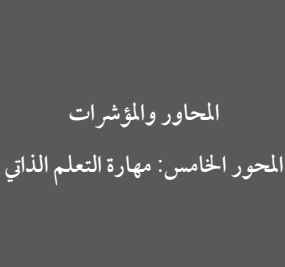 }} \\
\hline & & & المجموع & الدراسي الثاني & الفصل الدراسي & & \\
\hline & & & 793 & 404 & 389 & & \\
\hline 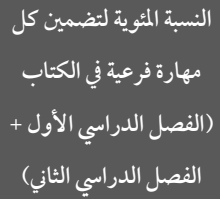 & اللفبة المئوية & اللفبة المئوية & المجموع & 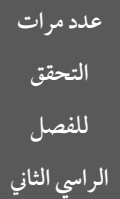 & $\begin{array}{c}\text { للفد مرات } \\
\text { للفحل الدراسي }\end{array}$ & & \\
\hline$\% 5.17$ & $\% 5.94$ & $\% 4.37$ & 41 & 24 & 17 & تشويع المحتوى المتعلم على & 23 \\
\hline$\% 13.49$ & $\% 15.84$ & $\% 11.05$ & 107 & 64 & 43 & تيقدم المحتوى أنشطة رياضية. & 24 \\
\hline$\% 7.06$ & $\% 6.43$ & $\% 7.71$ & 56 & 26 & 30 & يشجع المحتوئ استخدام. & 25 \\
\hline متضمنة بلرجة منخفضة & $\% 28.21$ & $\% 23.13$ & 204 & 114 & 90 & المجموع & \\
\hline
\end{tabular}


يتضح من الجدول (9) بأن النسبة المئوية لتضمين مهارة التعلم الذاتي في كتاب الرياضيات

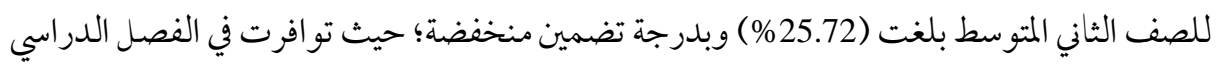
الأول بنسبة (23.13\%) وبدرجة تضمين منخفضة، وتوافرت بالفصل الدراسي الثاني بنسبة (28.21\%) وبدرجة تضمين منخفضة؛ حيث نجد أن مؤشر "يقدم المحتوى أنشطة رياضية تناسب أنماط التعلم

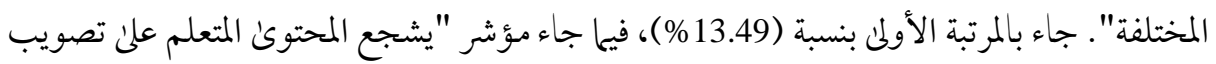

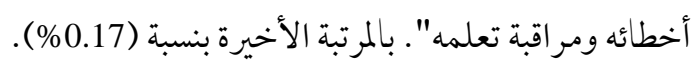
وتختلف هذه التيجة مع دراسة الغامدي (2015) والتي أظهرت أن توافر مهارات المهنة والتعلم المعتمد علن الذات جاءت بدرجة متوسطة في جميع كتب الرياضيات في الصفوف العليا: (الرابع، والخامس، والسادس) بالمملكة العربية السعودية، كما تتفق مع دراسة سبحي (2016) والتي

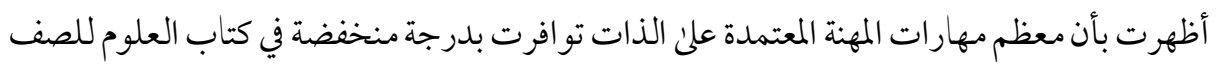

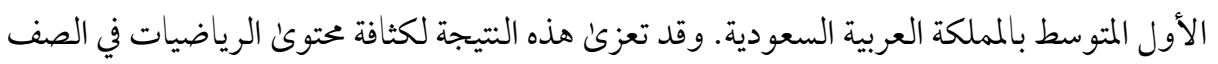

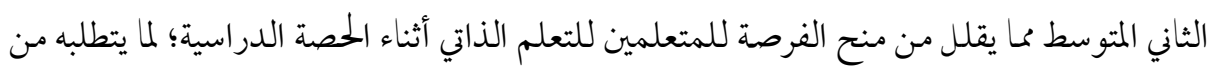

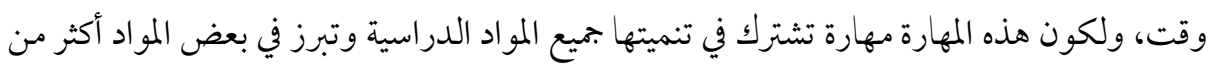

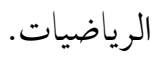


د. ححمد بن صنت بن صالح الحربي \& د. ناصر بن سليان بن ربيعان الحربي

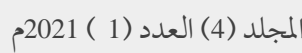

سادسًا: نتائج التحليل لمجال مهارة التعاون والمثاركة المجتمعية:

جدول (• (1) نتائج تحليل حتوى كتاب الرياضيات للصف الثاني المتوسط في ضوء تضمين مهارة التعاون والمشاركة المجتمعية

\begin{tabular}{|c|c|c|c|c|c|c|c|}
\hline \multirow{3}{*}{ 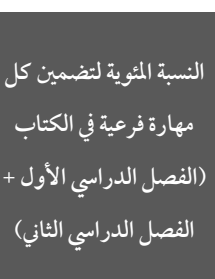 } & \multirow{3}{*}{ اللفبة المثوية } & \multirow{3}{*}{ النصبة المئوية } & \multicolumn{3}{|c|}{ إجمالي عدد الأفكار المتضمنة في الكتاب بشكل } & \multirow{3}{*}{\multicolumn{2}{|c|}{ 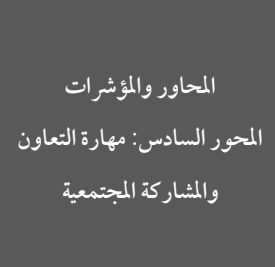 }} \\
\hline & & & المجموع & \begin{tabular}{|c|} 
الفصل الدراسي \\
\end{tabular} & الفصل الدراسي & & \\
\hline & & & 538 & 234 & 304 & & \\
\hline النسبة المثوية لتضمين كل & اللفبة المئوية & $\mid$\begin{tabular}{|c|}
$\mid$ النسبة المثوية \\
الدراسي الأول
\end{tabular} & المجموع| & |للف التصل الراسي & للفصل الدراسي & المؤشر & \\
\hline$\% 6.13$ & $\% 5.98$ & $\% 6.25$ & 33 & 14 & 19 & 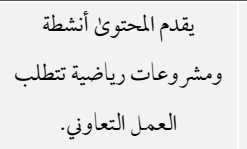 & 26 \\
\hline$\% 7.06$ & $\% 10.25$ & $\% 4.60$ & 38 & 24 & 14 & بمجوعات ختالفة في القدرات & 27 \\
\hline$\% 0$ & $\% 0$ & $\% 0$ & 0 & 0 & 0 & 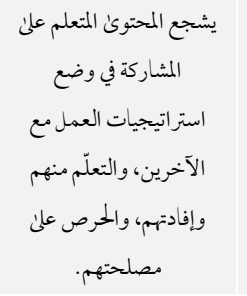 & 28 \\
\hline$\% 0.55$ & $\% 0.42$ & $\% 0.65$ & 3 & 1 & 2 & المشاركة المجتمعية مع اتبمعاع المتلن & 29 \\
\hline$\% 2.41$ & $\% 2.56$ & $\% 2.30$ & 13 & 6 & 7 & المشياضيات في حل بعض المحتو توظيف & 30 \\
\hline متضمنة بدرجة منخفضة 16.17 & $\% 19.23$ & $\% 13.81$ & 87 & 45 & 42 & المجموع & \\
\hline
\end{tabular}


يتضح من الجدول (10) بأن النسبة المئوية لتضمين مهارة التعاون والمشاركة الاجتماعية في كتاب الرياضيات للصف الثاني المتوسط بلغت (16.17\%) وبدرجة تضمين منخفض؛ حيث توافرت في الفصل الدراسي الأول بنسبة (13.81\%) وبدرجة تضمين منخفضة، وتو افرت بات بالفصل الدراسي الثاني بنسبة (19.23\%) وبدرجة تضمين منخفضة؛ حيث نجد أن مؤشر " يشجع المحتوكن العمل في

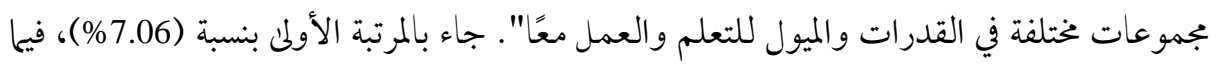
جاء مؤشر "يشجع المحتوىن المتعلم علن المشاركة في وضع استراتيجيات العمل مع الآخرين، والتعلّم

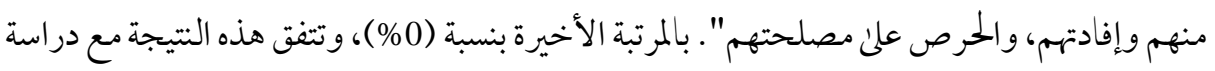

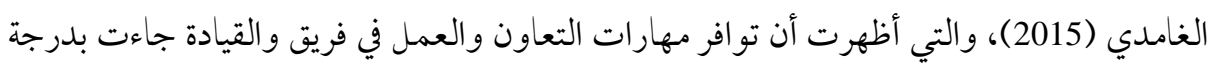

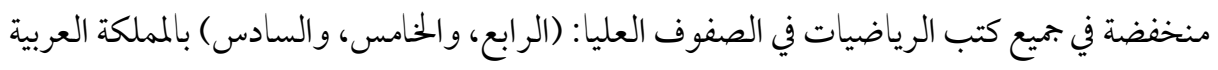

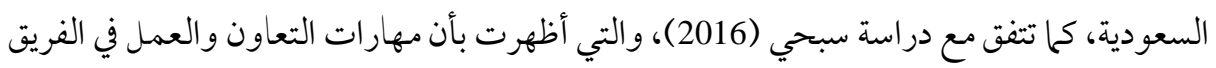
والقيادة توافرت بدرجة منخفضة في كتاب العلوم للصف الأول المتوسط بالمملكة العربية السعودية.

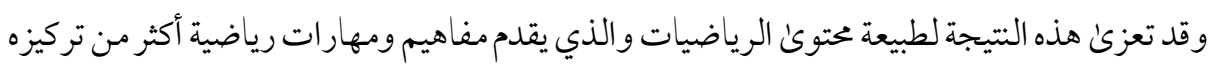

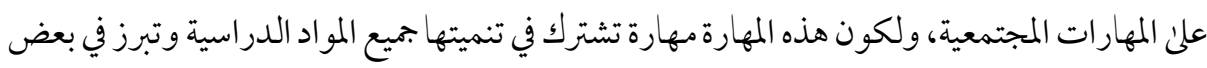

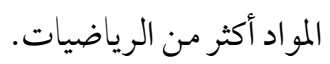


عرض ملخص لنتائج تحليل كتاب الرياضيات للصف الثاني المتوسط في ضوء تضمين مهارة القرن الحادي والعشرين: (2) - n

جدول (11) ملخص نتائج تحليل محتوىن كتاب الرياضيات للصف الثاني متوسط في ضوء تضمين مهارة القرن الحادي والعشرين

\begin{tabular}{|c|c|c|c|c|c|c|c|c|}
\hline \multirow{2}{*}{\multicolumn{2}{|c|}{ 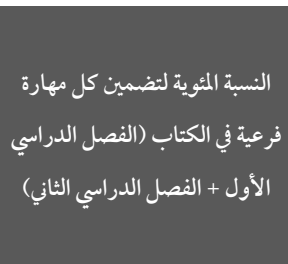 }} & \multirow{2}{*}{ 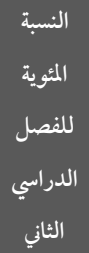 } & \multirow{2}{*}{ اللنصبة المؤية } & \multicolumn{3}{|c|}{ إجمالي عدد الأنكار المضضمنة في الكتاب } & \multirow[b]{3}{*}{ المهارات - لمات } & \\
\hline & & & & 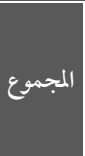 & الداسئ النصل & الدراسي الأول & & \\
\hline 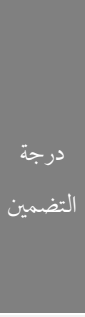 & كل المهارة فرعية في & 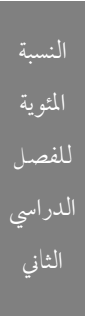 & اللفية المئوية & | المجموع & 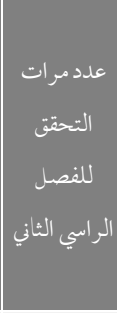 & اللداسي الألحل & & \\
\hline عالية & $\% 87.48$ & $\% 91.90$ & $\% 83.39$ & 944 & 477 & 467 & مهارة التفكير الناقدوحل & \\
\hline متوسطة & $\% 49.95$ & $\% 45.76$ & $\% 53.83$ & 522 & 227 & 295 & مهارة التفكير الإبداعي & 2 \\
\hline متوسطة & $\% 34.93$ & $\% 29.93$ & $\% 39.39$ & 349 & 141 & 208 & مهارة التواصل & 3 \\
\hline منخفضة & $\% 16.39$ & $\% 15.98$ & $\% 16.90$ & 79 & 43 & 36 & مهارة استخدام التقنية & 4 \\
\hline منخفضة & $\% 25.72$ & $\% 28.21$ & $\% 23.13$ & 204 & 114 & 90 & مهارة التعلم الذاتي & 5 \\
\hline منخفضة & $\% 16.17$ & $\% 19.23$ & $\% 13.81$ & 87 & 45 & 42 & مهارة التعاون والمشاركة & 6 \\
\hline متوسطة & $\% 38.44$ & & 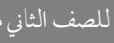 & 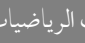 & 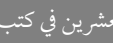 & : الحا & متوسط نسبة تضمين مهارا. & \\
\hline
\end{tabular}

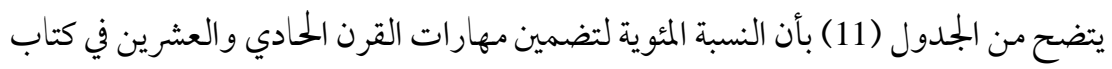

الرياضيات للصف الثاني المتوسط بلغت (38.44\%) وبدرجة تضمين متوسطة، حيث جاءت مهارة التفكير الناقد وحل المشكلات بالمرتبة الأولن بنسبة تضمين (87.48\%) وبدرجة تضمين عالية، بينما

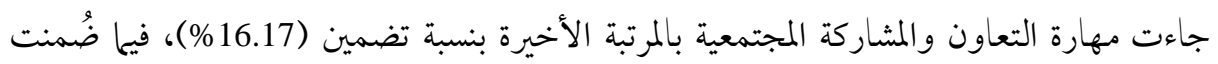
مهارتا: التفكير الإبداعي، والتواصل بدرجة متوسطة وبنسبة(49.95\%) و (34.93\%) على الترتيب، وضُمنت مهارتا: استخدام التقنية، والتعلم الذاتي بدرجة منخفضة وبنسبة(16.39\%) و (25.72\%) 
علن الترتيب. وتتفق هذه النتيجة مع نتيجة دراسة: (الغامدي، 2015)؛ حيث جاءت في المرتبة الأولى مهارات التفكير الناقد وحل المشكلات في جميع كتب الرياضيات في الصفوف العليا: (الرابع، والخمس، والسادس) بالمملكة العربية السعودية بنسبة(78.3\%) وبدرجة توافر عالية، وكذلك تتفق

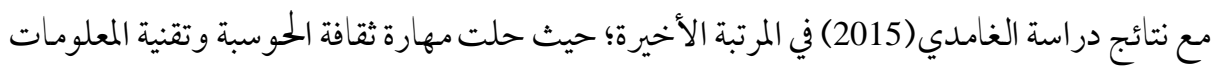

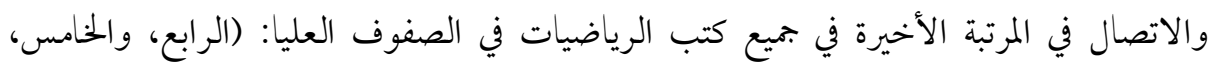

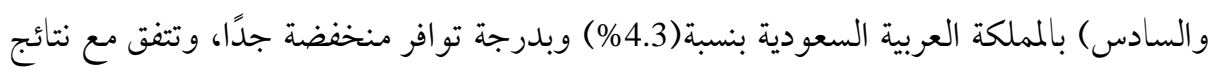

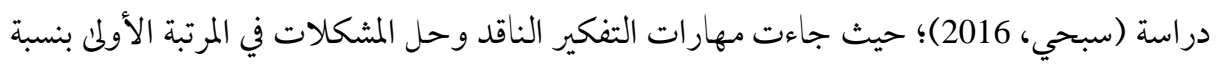
بلغت(72.6\%)، وتتفق مع نتائج دراسة (سبحي، 2016)؛ حيث جاءت في المرتبة ما قبل الأخيرة مهار ات التعاون والعمل في فريق واحد بنسبة بلغت (10.8\%)، كما تتفق مع دراسة (ملحمم، 2017) التي

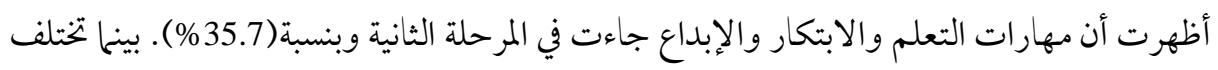

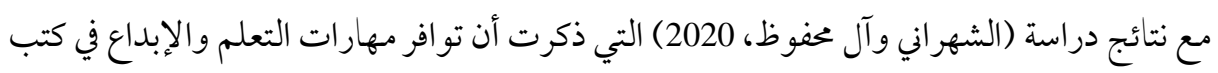
العلوم للمرحلة المتوسطة بدرجة ضعيفة في كتاب الصف الثاني المثتوسط.

ويعزو الباحثان تضمين مهارة التفكير الناقد وحل المشكلات ومهارة التفكير الإبداعي

بمستوى عال ومتوسط علن الترتيب في كتاب الرياضيات للصف الثاني المثو سط إلى طبيعية سلسلة

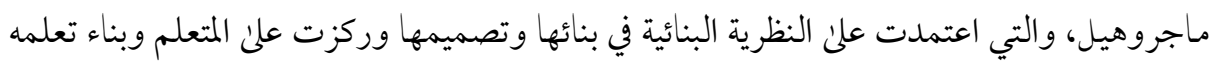
بنفسه، من خلال إتاحة الكثير من أنشطة الاستعداد والتهيئة والتدريبات والأمثلة التي تساعده علني

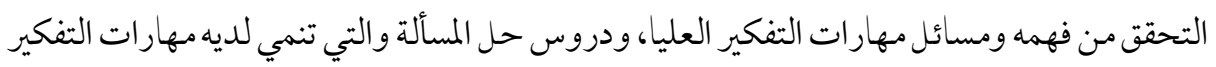

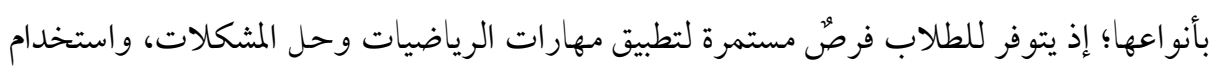

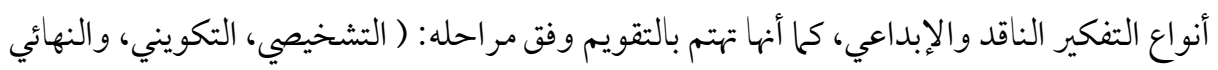

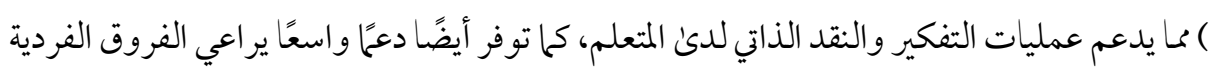

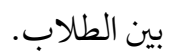




\section{توصيات البحث:}

يوصي الباحثان بها يلي:

- - الاستفادة من نتائج هذ البحث في تطوير كتب الرياضيات في ضوء مهارات القرن الحادي

$$
\text { و العشرين. }
$$

- - الاهتحام بمهارات استخدام التقنية والتعلم الذاتي والتعاون والمشاركة المجتمعية في كتب

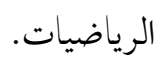

- - نشر ثقافة مهارات القرن الحادي والعشرين لدئ العاملين في الميدان التربوي، وخصوصًا

$$
\text { معلمي الرياضيات. }
$$

- تزويد معلمي ومشرفي الرياضيات بقائمة مهارات القرن الحادي والعشرين؛ ليستفيدوا منها

$$
\text { في تنفيذ الدروس والأشطة. }
$$

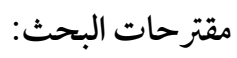

- إجراء دراسات تقويمية لكُتب الرياضيات في تضمينها لمهارات القرن الحادي والعشرين من وجهة نظر معلمي ومشرفي الرياضيات.

- دراسة مماثلة تحليلية أخرىن لكتاب الرياضيات للصف الرابع الابتدائي، في ضوء مهارات

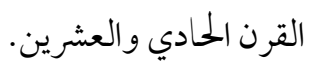

- - مراء دراسات تحليلية مماثلة لكتب الرياضيات لبقية صفوف المر حلة: المتوسطة، والابتدائية، و الثانوية.

- - ماعلية برنامج تدريبي في تنمية مهار ات القرن الحادي و العشري لدنأ معلمي الرياضيات. 


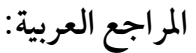

ا. إبراهيم، بجدي. (2002). المنطق والبرهان في تدريس الرياضيات. دار نهضة الشرق للنشر الشرئ

$$
\text { والتوزيع. }
$$

r. . البلوي، عواطف فالح، والبلوي، عائشة عمد. (2019). تصور لبرنامج تدريبي مقترح لتنمية بعض مهارات القرن الحادي والعشرين لدئ معلمات الرياضيات للمر حلة الابتدائية بمدينة تبوك. دراسات عربية في التربية وعلم النفس(ASEP)، مارس (107)، 386-433. r. ترلينج، بيرني، وفادل، تشارلز. (2013). تدريس مهارات القرن الحادي والعشرين: التعلم

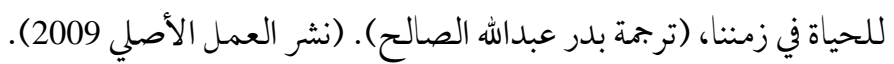

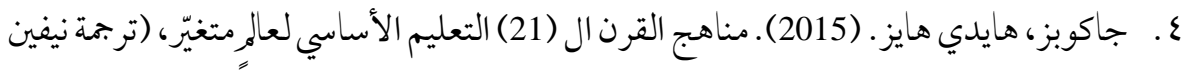

$$
\text { الزاغة). (نشر العمل الأصلي 2010). }
$$

ه. الحريري، رافدة. (2020). مهارات القرن الحادي والعشرين. المجلة الدولية للابنكارات

$$
\text { التربوية، } 8 \text { (1)، 70-91. }
$$

T. . الحصان، أماني محمد. (2017). المدخل التأسيسي للمناهج وطرق التدريس. مكتبة الرشد. V. . خليل، إبراهيم؛ والنذير، محمد. (2019). تصور مقترح لتضمين الرياضيات المجتمعية في كتب الرياضيات بالمرحلة الابتدائية العليا. بجلة تربويات الرياضيات.22(2)، 285-315.

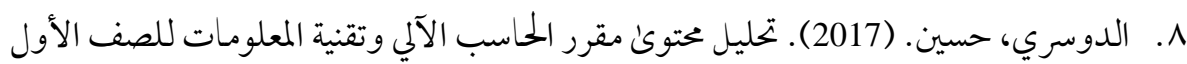

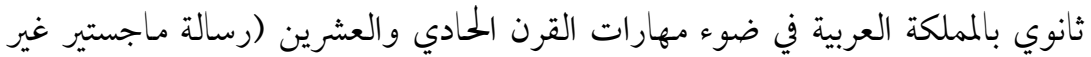
منشورة). جامعة الإمام عحمد بن سعود الإسلامية، الرياض.

9. الزهراني، عبدالعزيز عثمان. (2019). تصور مقترح لتطوير المارسات التدريسية لمعلمي الرياضيات في ضوءمهارات القرن الحادي والعشرين. مجلة جامعة أم القرىن للعلوم التربوية

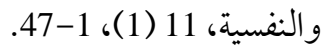


• ا ـ سبحي، نسرين حسن. (2016) . مدئ تضمين مهارات القرن الحادي والعشرين في مقرر العلوم

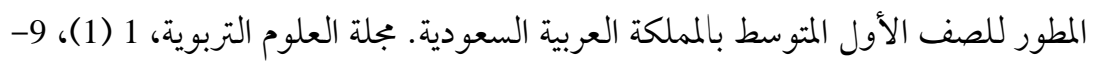

1 ا ـ سلبع، أمل. (2018) . مهارات القرن الحادي والعشرين و رؤية المملكة العربية السعودية 2030.

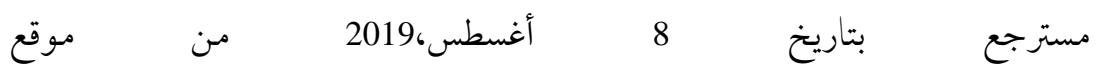
https://www.neweduc.com/author/amal-saleh r ا. الشمراني، صالح؛ الشمراني، سعيد؛ البرصان، إسلاعيل؛ الدرواني، بكيل. (2016). إضاءات

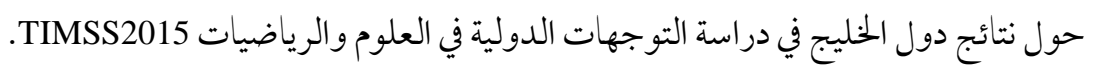
الرياض: مركز التميز البحثي في تطوير تعليم العلوم والرياضيات.

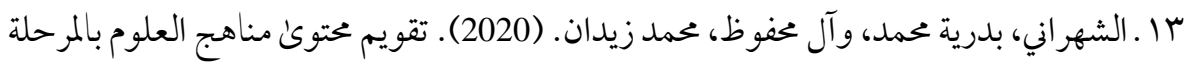

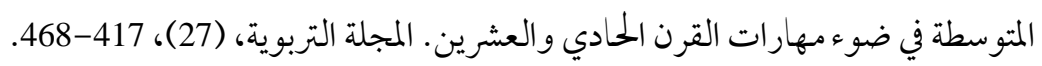

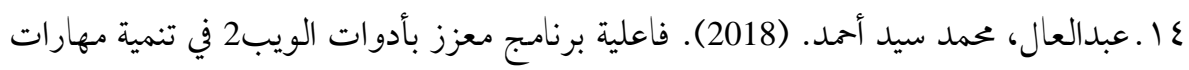

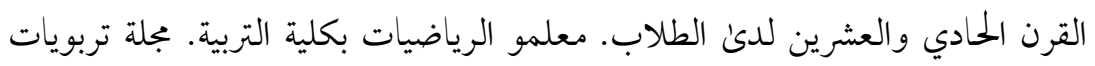

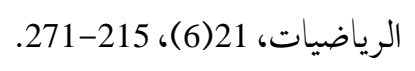

10 .عبيد، وليم. (2004). تعليم الرياضيات لجميع الأطفال في ضوء متطلبات. دار المسيرة للنشر والتوزيع. 7 ا ـ العساف، صالح حمد. (2010). المدخل إلى البحث في العلوم السلوكية. دار الزهراء.

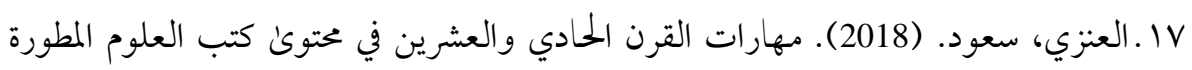
للمرحلة المتوسطة ومدئ إلمام الطلاب بها "دراسة تحليله" (رسالة ماجستير غير منشورة).

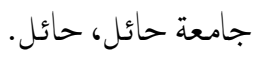

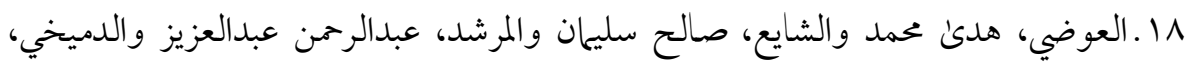

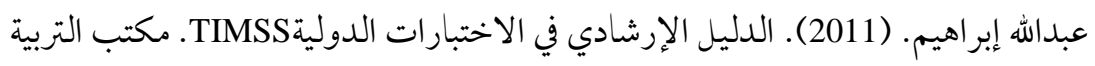
لدول الخليج. 
9 ا ـالغامدي، أريج. (2016). تطبيق نموذج SAMR و TPACK لدمسج التقنية داخل الفصول https://www.new-educ.com الدراسية. مسترجع بتاريخ 29 أغسطس،2019 من موقع • ·. الغامدي، حمدان؛ وعبدالجواد، نورالدين. (2015). تطوير نظام التعليم في المملكة العربية السعودية. مكتبة الرشد للنشر والتوزيع.

ا ا. الغامدي، محمد فهم. (2015). تحليل محتون كتب الرياضيات للصفوف العليا للمرحلة الابتدائية في ضوء مهارات القرن الحادي والعشرين. رسالة ماجستير غير منشورة، كلية

$$
\text { العلوم الاجتماعية، جامعة الإمام محمد بن سعود الإسلامية. }
$$

r Y. كساب، سناء. (2009). مستوئ جودة موضوعات المندسة المتضمنة في كتب رياضيات مرحلة التعليم الأساسي بفلسطين في ضوء معايير المجلس القومي لمعلمي الرياضيات (رسالة

$$
\text { ماجستير غير منشورة). الجامعة الإسلامية، غزة. }
$$

r r . محمود، مريرفت. (2015). مصادر تطوير تعليم الرياضيات. مركز ديبونو لتعليم التفكير. ع Y.مطر، محمد (2012). التقرير الجمعي حول مذكرات السياسات التربوية ضمن أنشطة تحليل بيانات دراسة TIMSS. بيروت: مكتب اليونسكو الإقليمي للتربية في الدول العربية. ه . ملحمم، أماني محمد. (2017). درجة تو افر مهارات القرن الحادي والعشرين في مقرر التكنولو جيا للمر حلة الأساسية العليا ودرجة امتلاك الطلبة لتلك المهارات. رسالة ماجستير غير منشورة، كلية الدراسات العليا، جامعة النجاح الوطنية. جr المؤتمر العلمي الخامس والدولي الثالث لكلية التربية. (2016). المدرسة المصرية في القرن الحادي والعشرين في ضوء الاتجاهات العالمية للتعليم، جامعة بورسعيد، مدارس بورسعيد الدولية،

$$
\text { 16- 16 أبريل. }
$$

VV r. الهويش، يوسف محمد. (2018). التنمية المهنية لمعلمي المملكة العربية السعودية، في ضوء مهار ات القرن الحادي والعشرين. مجلة كلية التربية-جامعة عين شمس، (42)، 247-282. 
^ץ. هيئة تقويم التعليم والتدريب. (2018). الإطار الوطني لمعايير مناهج التعليم العام في المملكة العربية السعودية. هيئة تقويم التعليم والتدريب للنشر.

هץ . هيئة تقويم التعليم والتدريب. (2019 أ). معايير مناهج التعليم العام. مسترجع بتاريخ 13

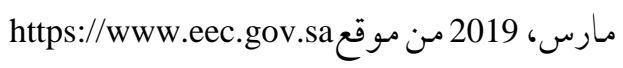

• r. هيئة تقويم التعليم والتدريب. (2019ب). الإطار التخصصي لمجال تعلم الرياضيات. الرياض: هيئة تقويم التعليم و التدريب للنشر.

اب. وزارة التعليم. (2019). التعليم ورؤية المملكة العربية السعودية (2030). مسترجع بتاريخ 1 https://www.moe.gov.sa/ar/Pages/vision2030.aspx مارس، 2019 من موقع 


\section{References:}

- Abdel Aal, Mohamed Sayed Ahmed. (2018). The effectiveness of a program enhanced with web-2 tools in developing students' twenty-first century skills. Mathematics teachers at the College of Education. Journal of Pedagogical Mathematics, 21 (6), 215-271.

- $\quad$ Al-Anzi, Saud. (2018). The skills of the twenty-first century in the content of developed science books for the intermediate level and the extent of students' familiarity with them," Analytical study "(unpublished master's thesis). University of Hail, Hail.

- Al-Awadi, Hoda Muhammad and Al-Shaya, Salih Suleiman and Al-Murshid, Abdul-Rahman Abdul-Aziz and Al-Damikhi, Abdullah Ibrahim. (2011). TIMSS guide. Riyadh: The Education Office for the Gulf States.

- $\quad$ Al-Balawi, Awatef Faleh, Al-Balawi, Aisha Muhammad. (2019). Envisioning a proposed training program to develop some of the twenty-first century skills for primary school mathematics teachers in Tabuk. Arab Studies in Education and Psychology (ASEP), March (107), 386-433.

- Al-Dossary, Hussein. (2017). Analyzing the content of the computer and information technology course for the first secondary school year in the Kingdom of Saudi Arabia in the light of twenty-first century skills (unpublished master's thesis). Imam Muhammad bin Saud Islamic University, Riyadh.

- $\quad$ Al-Ghamdi, Areej. (2016). Apply SAMR and TPACK to technology integration in the classroom. Retrieved August 29, 2019. https://www.new-educ.com

- Al-Ghamdi, Hamdan; Abdel-Jawad, Noureddine. (2015). Development of the education system in the Kingdom of Saudi Arabia. Al-Rushd Library for Publishing and Distribution.

- Al-Ghamdi, Mohamed Fahm. (2015). Analyzing the content of mathematics books for the upper grades of elementary school in light of twenty-first century skills. Unpublished Master Thesis, College of Social Sciences, Imam Muhammad bin Saud Islamic University. 


$$
\text { د. محمد بن صنت بن صالح الحربي \& د. ناصر بن سليهان بن ربيعان الحربي }
$$

- Al-Howaish, Yusef Muhammad. (2018). Professional development for teachers in the Kingdom of Saudi Arabia, in light of the twenty-first century skills. Journal of the College of Education - Ain Shams University, (42), 247-282.

Alhusan, Amani Muhammad. (2017). Foundational approach to curriculum and teaching methods. Al-Rushd Library.

- Al-Shahrani, Badria Mohamed, and Al Mahfouz, Muhammad Zaidan. (2020). Evaluating the content of science curricula at the intermediate level in light of the twenty-first century skills. The Educational Journal, (27), 417-468.

- $\quad$ Alshamrani, Saleh; Alshamrani, Saeed; Albursan, Ismail; Al-Darwani, Bekeel. (2016). Highlights on the results of the Gulf countries in the Study of International Trends in Science and Mathematics TIMSS 2015. Riyadh: Center of Excellence for Research in the Development of Science and Mathematics Education.

- Al-Zahrani, Abdulaziz Othman. (2019). A proposed vision for developing the teaching practices of mathematics teachers in light of the skills of the twenty first century. Umm Al-Qura University Journal of Educational and Psychological Sciences, 11 (1). 1-47.

- Assaf, Saleh Hamad. (2010). Introduction to research in the behavioral sciences. Dar Al Zahraa.

- $\quad$ Drake, S. M., \& Reid, J. L. (2018). Integrated curriculum as an effective way to teach 21 st century capabilities. Asia Pacific Journal of Educational Research, 1(1), 31-50.

- Education and Training Evaluation Authority. (2019a). General Education Curriculum Standards. Retrieved March 13, 2019.Retrieved from https://www.eec.gov.sa

- Education and Training Evaluation Commission. (2018). The National Framework for Curriculum Standards for General Education in the Kingdom of Saudi Arabia. Education and Training Evaluation Commission for publication. 
- Education and Training Evaluation Commission. (2019b). Specialized framework for mathematics learning. Riyadh: Education and Training Evaluation Commission for Publication.

- $\quad$ El Mawas, N; Bradford, M; Andrews, J, Pathak, P; \& Hava, C. (2012). A Case Study on 21st Century Skills Development Through a Computer Based Maths Game. National College of Ireland, IrelandPokhrel.

- $\quad$ Gravemeijer, K., Stephan, M., Julie, C., Lin, F. L., \& Ohtani, M. (2017). What mathematics education may prepare students for the society of the future?. International Journal of Science and Mathematics Education, 15(1), 105-123.

- $\quad$ Gravemeijer, K., Stephan, M., Julie، C., Lin, F. L.,\& Ohtani, M. (2017). What mathematics education may prepare students for the society of the future?. International Journal of Science and Mathematics Education, 15(1), 105-123.

- Hariri, transom. (2020). Twenty-first century skills. International Journal of Educational Innovations, 8 (1), 70-91.

- $\quad$ Ibrahim, Magdy .(2002). Logic and proof in teaching mathematics. Dar Nahdat Alsharq for Publishing and Distribution.

- Jacobs, Heidi Hayes. (2015). 21st Century Curricula: Basic Education for a Changing World, (Nevin Zagha's translation). (Original work in 2010 AD).

- Kassab, Sana. (2009). Quality level of engineering subjects included in basic education mathematics textbooks in Palestine in light of the standards of the National Council of Mathematics Teachers (unpublished master's thesis). Islamic University of Gaza.

- $\quad$ Khalil Ibrahim; And Al-Nathir , Muhammad. (2019). A proposed scenario to include community mathematics in mathematics textbooks at the upper primary level. Journal of Pedagogical Mathematics 22 (2), 285-315.

- Mahmoud, Mererft. (2015). Resources for developing mathematics education. Debono Center for Teaching Thinking. 


$$
\text { د. محمد بن صنت بن صالح الحربي \& د. ناصر بن سليهان بن ربيعان الحربي }
$$

- Matar, Muhammad (2012). The combined report on the educational policy notes within the activities of the TIMSS data analysis. Beirut: UNESCO Regional Office for Education in the Arab States.

- Melhem, Amani Mohammed. (2017). The degree of availability of twenty-first century skills in the technology course for the higher basic stage and the degree to which students possess these skills. Unpublished MA Thesis, College of Graduate Studies, An-Najah National University.

- $\quad$ Ministry of education. (2019). Education and the vision of the Kingdom of Saudi Arabia (2030 AD). Retrieved on March 1, 2019.Retrieved from https://www.moe.gov.sa/ar/Pages/vision2030.aspx

- Obaid, William. (2004). Teaching mathematics to all children in light of the requirements. Dar Al-Maseerah for Publishing and Distribution.

- $\quad$ Organisation for Economic Co-operation and Development [OECD] .(2019). PISA 2018 Results (Volume I): What Students Know and Can Do، PISA، Paris: OECD Publishing. https://doi.org/10.1787/5f07c754-en.

- $\quad$ Rizki, L. M. \& Priatna, N. (2019). Mathematical literacy as the 21st century skill. Departement Pendidikan Matematika، Sekolah Pascasarjana، University of Education Indonesia، Indonesia International Conference on Mathematics and Science Education. (ICMScE 2018), Journal of Physics.

- $\quad$ Salbaa, Amal. (2018). 21st Century Skills and Saudi Arabia's Vision 2030. Retrieved on August 8, 2019 from https://www.neweduc.com/author/amalsaleh

- Subhi Nisreen Hassan. (2016). The extent to which twenty-first century skills are included in the developed science course for the first intermediate grade in the Kingdom of Saudi Arabia. Journal of Educational Sciences, 1 (1), 9-44.

- The Fifth Scientific Conference and Third International one of the College of Education. (2016). The Egyptian School in the Twenty-First Century in the Light of Global Education Trends, Port Said University, Port Said International Schools, April 16-17. 
- $\quad$ Trilling, Bernie, and Fadel, Charles. (2013). Teaching the skills of the twentyfirst century: learning for life in our time, (translated by Badr Abdullah AlSaleh). (Original work in 2009 CE). P. 48.

- Warner, S., \& Kaur, A. (2017). The Perceptions of Teachers and Students on a 21st Century Mathematics Instructional Model. International Electronic Journal of Mathematics Education, 12(2), 193-215.

- Yogi, A; Ishak, A, \& Rusman. (2018). The Development of Mathematics Curriculum to Increase the Higher Order Thinking Skills in The 21st Century Era. Department of Curriculum Development, University of Education, Bandung, Indonesia, International Council for Scientific and Technical Information، ICSTI 2018, October 19-20, Yogyakarta, Indonesia. 
